\title{
The Mycoheterotrophic Symbiosis Between Orchids and Mycorrhizal Fungi Possesses Major Components Shared with Mutualistic Plant-Mycorrhizal Symbioses
}

\author{
Chihiro Miura, ${ }^{1}$ Katsushi Yamaguchi, ${ }^{2}$ Ryohei Miyahara, ${ }^{1}$ Tatsuki Yamamoto, ${ }^{3}$ Masako Fuji, ${ }^{1}$ \\ Takahiro Yagame, ${ }^{4}$ Haruko Imaizumi-Anraku, ${ }^{5}$ Masahide Yamato, ${ }^{6}$ Shuji Shigenobu, ${ }^{2}$ and \\ Hironori Kaminaka ${ }^{1, \dagger}$
}

\begin{abstract}
${ }^{1}$ Faculty of Agriculture, Tottori University, Tottori, Japan; ${ }^{2}$ Functional Genomics Facility, NIBB Core Research Facilities, National Institute for Basic Biology, Okazaki, Japan; ${ }^{3}$ Graduate School of Agriculture, Tottori University, Tottori, Japan; ${ }^{4}$ Mizuho Kyo-do Museum, Tokyo, Japan; ${ }^{5}$ Institute of Agrobiological Sciences, National Agriculture and Food Research Organization, Tsukuba, Japan; and ${ }^{6}$ Faculty of Education, Chiba University, Chiba, Japan
\end{abstract}

Accepted 10 April 2018.

Achlorophylous and early developmental stages of chorolophylous orchids are highly dependent on carbon and other nutrients provided by mycorrhizal fungi, in a nutritional mode termed mycoheterotrophy. Previous findings have implied that some common properties at least partially underlie the mycorrhizal symbioses of mycoheterotrophic orchids and that of autotrophic arbuscular mycorrhizal (AM) plants; however, information about the molecular mechanisms of the relationship between orchids and their mycorrhizal fungi is limited. In this study, we characterized the molecular basis of an orchidmycorrhizal (OM) symbiosis by analyzing the transcriptome of Bletilla striata at an early developmental stage associated with the mycorrhizal fungus Tulasnella sp. The essential components required for the establishment of mutual symbioses with AM fungi or rhizobia in most terrestrial plants were identified from the $B$. striata gene set. A cross-species gene complementation analysis showed one of the component genes, calcium and calmodulin-dependent protein kinase gene $C \mathrm{CaMK}$ in B. striata, retains functional characteristics of that in AM plants. The expression analysis revealed the activation of homologs of

Nucleotide sequence data from the RNA-seq analysis and genome sequencing analysis in this study have been deposited into the DNA Data Bank of Japan Sequence Read Archive under the accession numbers DRA005999 and DRA006009, respectively.

${ }^{\dagger}$ Corresponding author: Hironori Kaminaka;

E-mail: kaminaka@tottori-u.ac.jp

Funding: This work was supported by the National Institute for Basic Biology Cooperative Research Programs (Next-Generation DNA Sequencing Initiative: 13-733, 14-702, 15-825, 16-430, and 17-430), a Grantin-Aid for Scientific Research on Innovative Areas "Genetic Bases for the Evolution of Complex Adaptive Traits" from The Ministry of Education, Culture, Sports, Science and Technology (MEXT) (MEXT grant numbers KAKENHI 25128710 and KAKENHI 22128001), a Grant-in-Aid for Challenging Exploratory Research from the Japan Society for the Promotion of Science (JSPS) (JSPS grant number KAKENHI 15K14550), and the Tottori Prefecture Research Fund for the Promotion of Environmental Academic Research to H. Kaminaka.

*The $\boldsymbol{e}$-Xtra logo stands for "electronic extra" and indicates that four supplementary figures, nine supplementary tables, and one supplementary dataset are published online.

@ 2018 The American Phytopathological Society
AM-related genes during the OM symbiosis. Our results suggest that orchids possess, at least partly, the molecular mechanisms common to AM plants.

Plants form symbioses with a wide range of microorganisms such as mycorrhizal fungi or nitrogen-fixing bacteria to facilitate their acquisition of nutrients (Martin et al. 2017). Arbuscular mycorrhizal (AM) symbiosis is a widespread mutualistic association between land plants and fungi of the subphylum Glomeromycotina (Parniske 2008; Smith and Read 2008; Spatafora et al. 2017), in which the resource exchange basically relies on a reciprocal "fair trade" (Kiers et al. 2011), although there are certainly some exceptions (Imhof et al. 2012). In contrast to this mutual symbiosis, some plants unilaterally depend on mycorrhizal fungi for their nutritional needs, including carbon and other essential nutrients. This parasitic nutritional mode, termed mycoheterotrophy (Leake 1994), occurs in most major groups of land plants, including liverworts, lycophytes, ferns, and angiosperms (Merckx 2012). A wide range of fungi, including species of Glomeromycotina, Ascomycota, and Basidiomycota, is known as the fungal partner for the mycoheterotrophic plants (Merckx 2012).

The family Orchidaceae, which at 25,000 species is one of the largest families of flowering plants (Atwood 1986; Chase et al. 2015), has the most mycoheterotrophic genera of any plant family (Leake 1994; Merckx 2012). Orchids are dependent on carbon, nitrogen, and phosphorus sources provided by mycorrhizal fungi (Cameron et al. 2006, 2007; Kuga et al. 2014), at least during their germination, a characteristic classified as initial mycoheterotrophy (Merckx 2012). Although many initial mycoheterotrophs develop into autotrophic mature plants, some orchids continue to obtain carbon from mycorrhizal fungi throughout their lifecycle (full mycoheterotrophy) or utilize both photosynthesis and mycoheterotrophy at maturity (partial mycoheterotrophy) (Dearnaley et al. 2016; Merckx 2012). Recent studies have provided some evidence that bidirectional transfer of nutrients occurs in adult orchids (Cameron et al. 2006, 2008; Suetsugu et al. 2017), suggesting that the fidelity of fungal partners may enable them to gain long-term benefits (Leake et al. 2008). Among orchid-mycorrhizal (OM) symbioses, the majority of orchids interact with the polyphyletic Rhizoctonia fungi that are saprotrophic (Martos et al. 2009; Ogura-Tsujita et al. 2009) or possibly root endophytic fungi 
(Rasmussen and Rasmussen 2007; Selosse and Martos 2014). The initial mycoheterotrophic dependency on Rhizoctonia fungi is likely the ancestral state of the Orchidaceae family, and it has been hypothesized that the unique ability of orchids to recruit free-living saprotrophic fungi into novel mycorrhizas may have dramatically expanded their potential habitat and triggered their radiation (Givnish et al. 2015; Merckx 2012; Ogura-Tsujita et al. 2009).

Recent studies have reported that genes related to AM symbiosis such as GRAS-domain transcription factor genes, nodulin-like genes, and the auxin efflux facilitator gene PIN1 can be activated during the formation of mycoheterotorophic symbioses in the young seedling (protocorm) stage of autotrophic (i.e., initially mycoheterotrophic) and partially mycoheterotrophic orchids (Perotto et al. 2014; Suetsugu et al. 2017; Zhao et al. 2013). Some partially mycoheterotrophic orchids such as Epipactis spp. produce fully achlorophyllous variants that can reach almost the same size as their green counterparts due to the ability to obtain carbon from their symbiotic fungi (Selosse and Roy 2009). Because the achlorophyllous variants exhibit an increased dependence on mycorrhizal fungi (Selosse and Roy 2009; Suetsugu et al. 2017), genes upregulated in the mycorrhizal roots of the achlorophyllous variants could be important for the establishment of symbiosis. Our previous research, comparing the root transcriptomes of partially mycoheterotrophic orchid Epipactis helleborine and their achlorophyllous mutants, demonstrated that genes required for AM colonization such as genes encoding a glycerol-3-phosphate acyltransferase (REQUIRED FOR ARBUSCULAR MYCORRHIZA2) and subtilisin are more highly expressed in the achlorophyllous variants than in green E. helleborine individuals (Suetsugu et al. 2017). Moreover, genes related to gibberellin biosynthesis are downregulated in the achlorophyllous variants, which is notable because gibberellin reduces hyphal colonization and arbuscule formation during AM symbiosis (Takeda et al. 2015). These previous findings imply that the mycorrhizal symbioses of mycoheterotrophic orchids share at least some common properties with AM-forming autotrophic plants (Perotto et al. 2014; Suetsugu et al. 2017); however, our understanding of the molecular basis of the OM symbiosis is limited (Fochi et al. 2017; Perotto et al. 2014; Zhao et al. 2013; Zhao et al. 2014).

In molecular studies of mycorrhizal symbioses, it is well known that a set of common symbiosis genes (CSG) is involved in the signaling pathway for the perception and transduction of diffusible microbial signals during root colonization and nutrient exchange in angiosperms. CSG were initially reported to be required for the establishment of not only rhizobium-legume (RL) symbiosis but also AM symbiosis in leguminous plants (Genre and Russo 2016; Kistner et al. 2005; Stougaard 2001) and, recently, a third symbiosis involving nitrogen-fixing actinorrhizas was also found to require CSG (Genre and Russo 2016). The CSG in the legume Lotus japonicus encode the symbiosis receptor-like kinase SYMRK; cation channels CASTOR and POLLUX; nucleoporins NUP85, NUP133, and SEC13 HOMOLOG1 (SEH1) NENA; the calcium and calmodulindependent protein kinase CCaMK; and the calcium signaldecoding protein CYCLOPS (Genre and Russo 2016). CSG mutants have a symbiosis-defective phenotype because the early symbiotic signaling pathway is blocked (Groth et al. 2010; Imaizumi-Anraku et al. 2004; Kanamori et al. 2006; Saito et al. 2007; Stracke et al. 2002; Tirichine et al. 2006; Yano et al. 2008). Candidates for orthologs of CSG have been computationally predicted to be present not only in the genomes of a number of dicot and monocot AM plants that form mutualistic symbiosis with AM fungi but also in the charophyte algae, whose ancestral lineage gave rise to the land plants (Delaux et al. 2013, 2014, 2015; Zhu et al. 2006). In contrast, it was reported that non-AM plants such as members of the families Brassicaceae and Pinaceae generally have a defective or partial set of CSG (Delaux et al. 2014; Garcia et al. 2015). The sequences and functional conservation of CSG in orchids remains unknown.

We previously reported a method for inducing the symbiotic germination of Bletilla striata (Orchidaceae), which is an initially mycoheterotrophic plant species, with a symbiotic fungus Tulasnella sp. strain HR1-1, hereafter referred to as Tulasnella (Yamamoto et al. 2017). This method is suitable for quantitative analyses because the $B$. striata seed germinate rapidly and synchronously. Here, we use this method to enable the description of the CSG and the characterization of the molecular basis of OM symbiosis by analyzing transcriptome profiles of $B$. striata symbiotic protocorms. We also explored the functional conservation of the CSG and its concomitant expression in this orchid by performing a cross-species complementation of CCaMK and by analyzing the expression of $B$. striata genes identified as orthologs of AM-inducible marker genes in rice (Gutjahr et al. 2008).

\section{RESULTS}

RNA sequencing of $B$. striata symbiotic protocorms and genome sequencing of Tulasnella.

In orchid mycorrhizae, fungal hyphae colonize protocorm or root cells. The hyphae enter parenchyma cells, branch to form dense hyphal coils called pelotons, and are ultimately degraded. A protocorm infected with mycorrhizal fungi contains dozens of symbiotic cells. Each of these symbiotic cells can be classified into three stages according to the morphological characteristics of their fungal symbionts (Yamamoto et al. 2017). The early stage is characterized by fungal invasion and the formation of pelotons within the cortical cells, the middle stage is characterized by well-developed pelotons with a clear fungal cell wall, and the late stage is characterized by the disruption of the peloton. These symbiotic cells in the protocorm were observed at least 1 week after the symbiotic germination of B. striata with Tulasnella and most of the symbiotic cells are at the early stage at that time (Yamamoto et al. 2017). After that, the total number of symbiotic cells in a protocorm continue to increase during the first 3 weeks. The symbiotic cells at the middle and late stages were the most frequently observed after 2 and 3 weeks of symbiotic germination, respectively (Yamamoto et al. 2017). Therefore, we collected samples of the B. striata protocorms at each of these ages to compare their transcriptomes using RNA sequencing. The RNA sequencing run produced 4.8 to 14.9 million reads per sample. We assembled the total reads into contigs and predicted 77,768 nonredundant open reading frames (Supplementary Table S1).

To classify the reads and nonredundant gene sets into sequences of plant and fungal origin, we sequenced the Tulasnella genome using Illumina sequencing technology. The obtained assembly contained 15,642 scaffolds with $65.9 \mathrm{Mb}$ of sequence data (Supplementary Table S2). Using the fungal assembly, we classified the reads from the RNA sequencing of the symbiotic protocorm into paired or unpaired reads, which therefore originated from the fungus or plant, respectively. On average, $87.5 \pm$ $2.0 \%$ of reads were found to have a putative plant origin. The de novo reference assembly of plant-derived sequences was confirmed by subtracting the result of a BLAST search of the assembled genome scaffolds of Tulasnella from the nonredundant gene sets. We then extracted 59,143 coding sequences that were determined to be of plant origin.

\section{Identification of a set of putative common symbiotic genes in B. striata.}

To determine whether B. striata possesses a set of CSG, we searched for orthologs of CSG from other plant species in the 

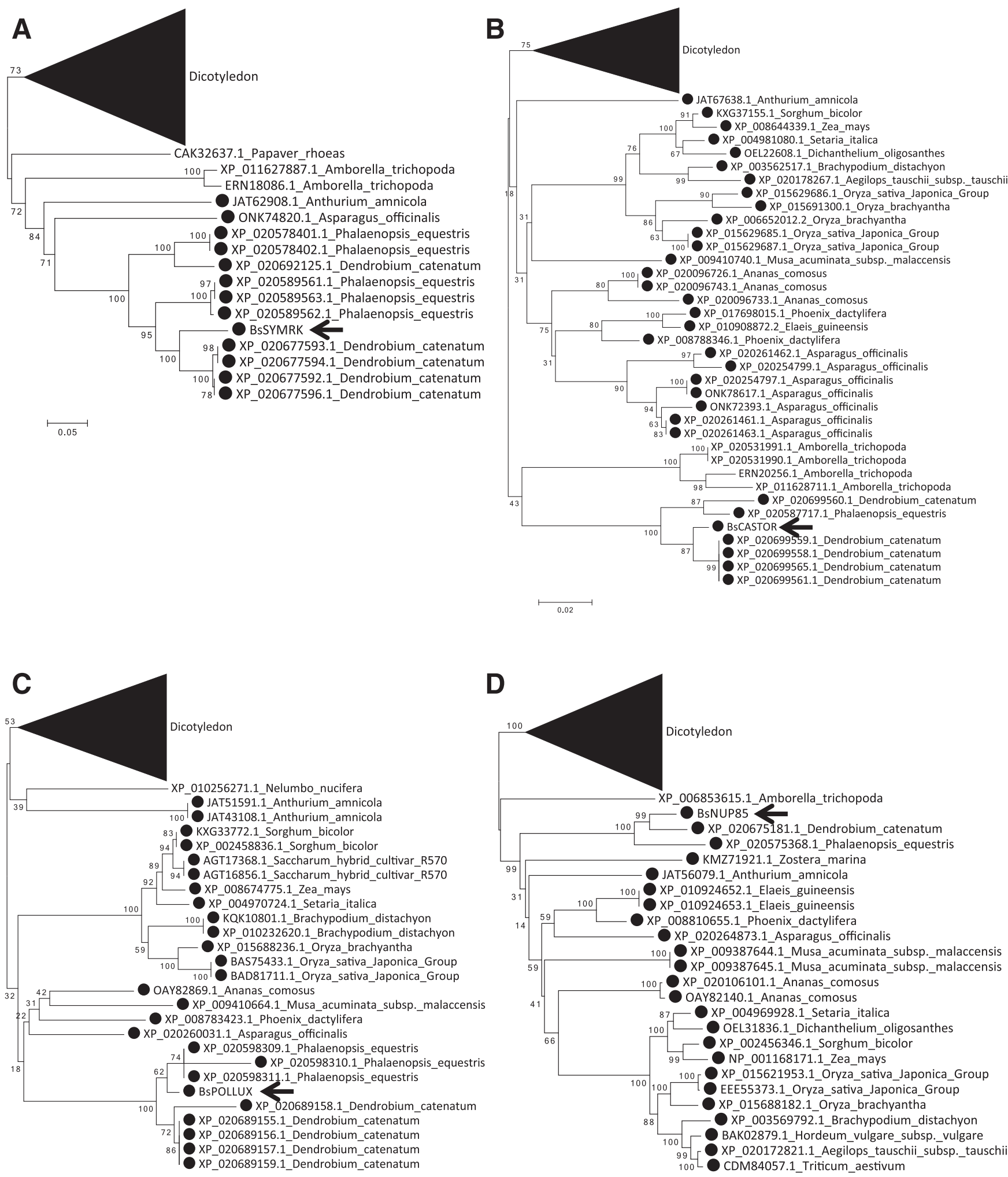

(Continued)

Fig. 1. Phylogenetic relationships of common symbiosis genes in Bletilla striata and a variety of other plant species. Neighbor-joining trees show the phylogenetic relationships among the protein sequences of A, SYMRK; B, CASTOR; C, POLLUX; D, NUP85; E, NUP133; F, NENA; G, CCaMK; and H, CYCLOPS. Accession numbers from the National Center for Biotechnology Information Reference Sequence are given for all sequences. Black filled circles represent monocotyledonous species. Arrows indicate the B. striata genes. Phylogenetic trees were constructed using MEGA software version 7 . 
Fig. 1. (Continued from previous page)
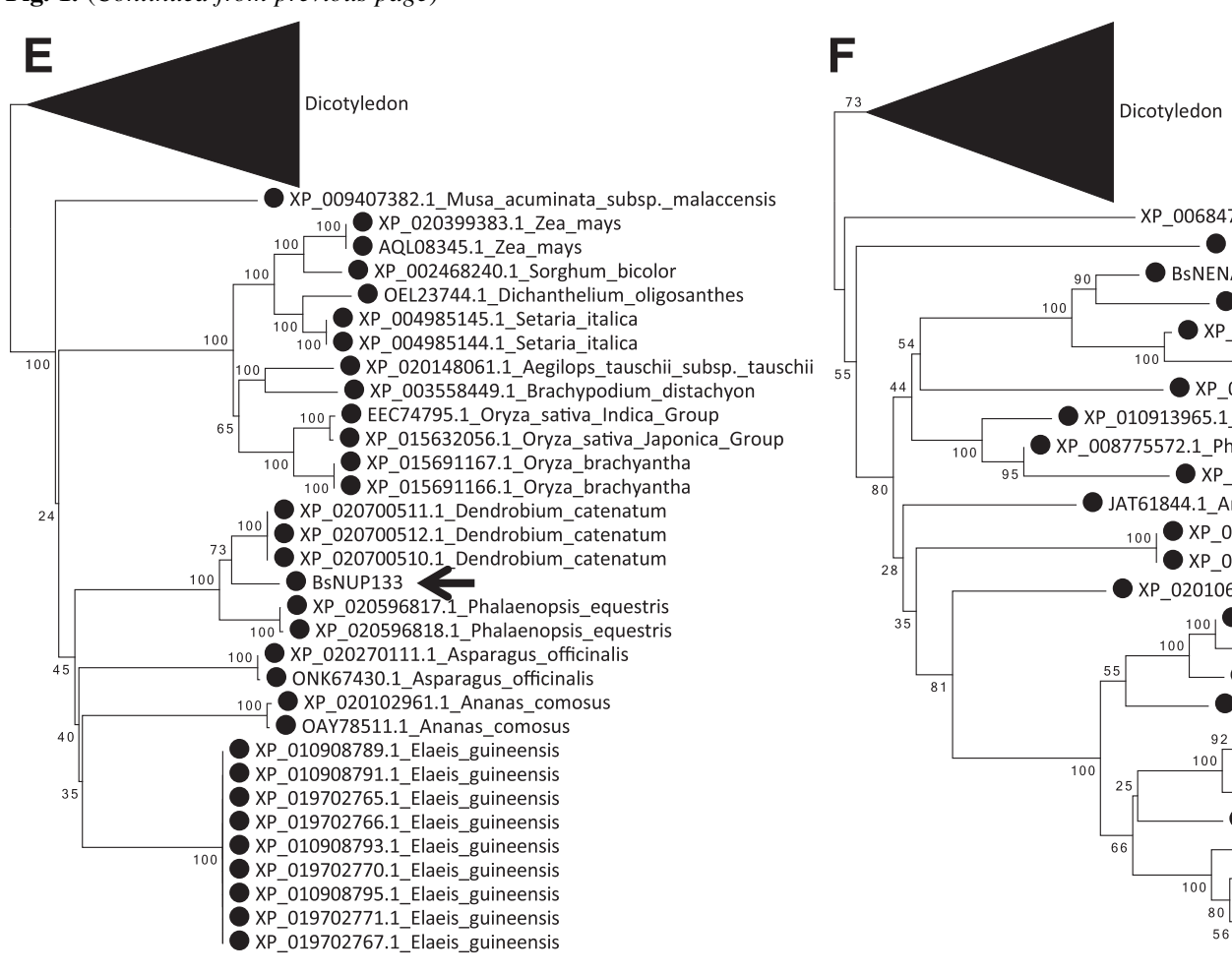

100100 XP_020399383.1_Zea_mays

AQL08345.1_Zea_mays

Dichanthelium oligosanthes
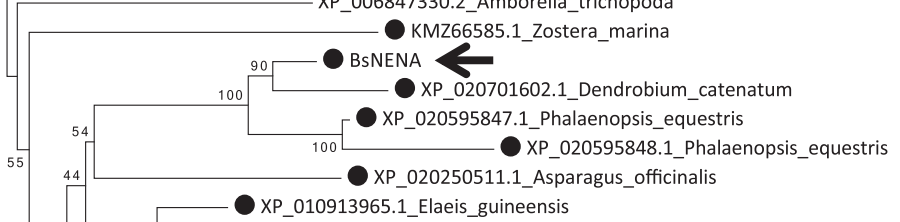

80 XP_008775572.1_Phoenix_dactylifera

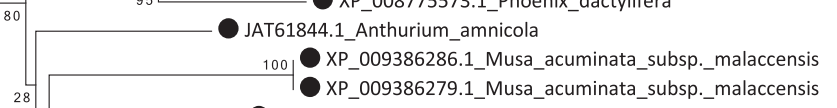
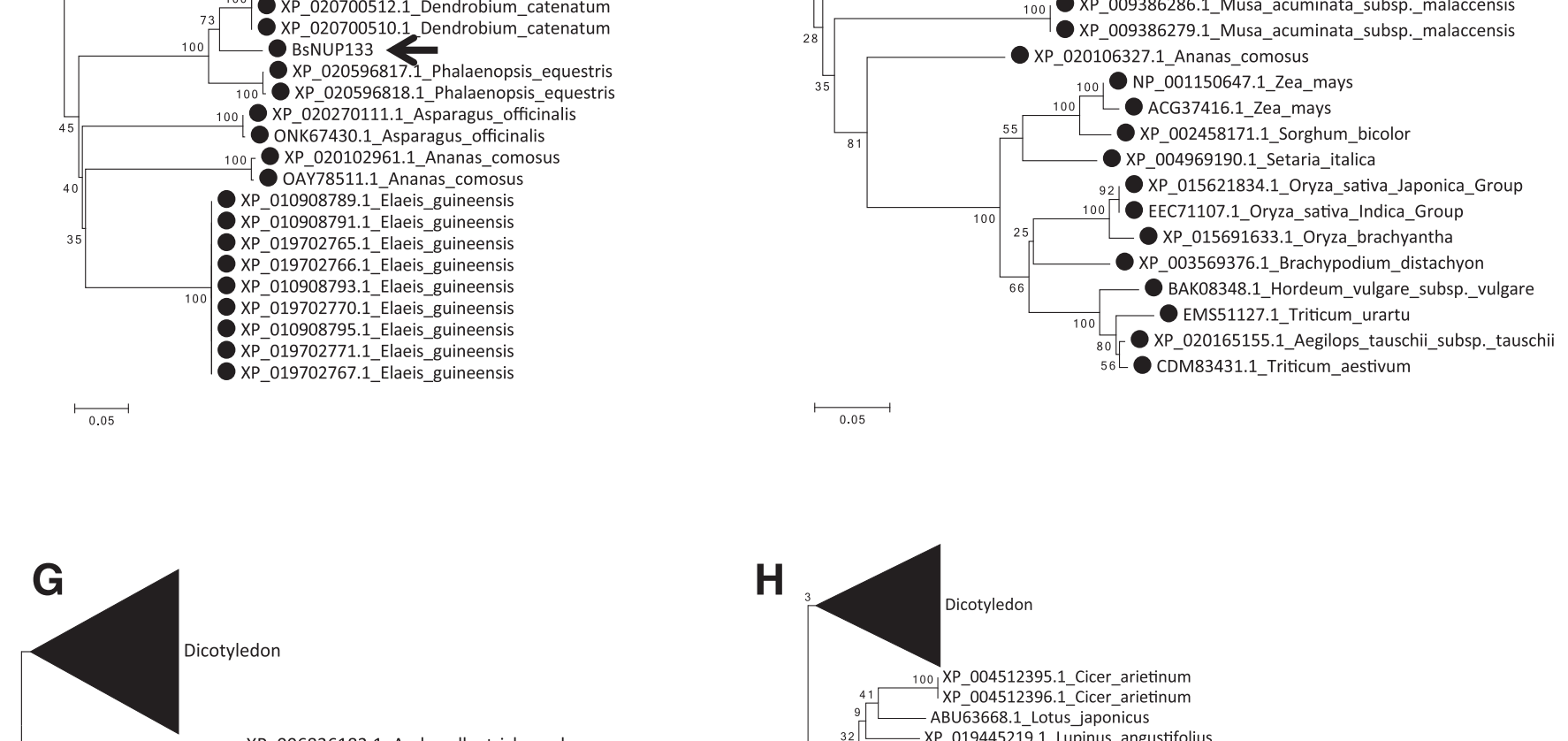
$100[$ XP_006836183.1_Amborella_trichopoda
ADV78082.1_Amborella_trichopoda
OJAT61842.1_Anthurium_amnicola

JAT61842.1_Anthurium_amnicola

99 Q43531.1_Lilium_longiflorum

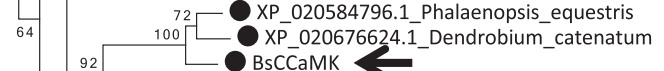

XP_020676624.1_Dendrobium_ca
BsCCaMK 020253646.1 Asparagus officinalis

74 XP_020253646.1_Asparagus_officinalis

44 X8 100 XP_020102239.1_Ananas_comosus

44 OAY85653.1_Ananas_comosus

${ }_{100}$ XP_010922946.1_Elaeis_guineensis

XP_019705924.1_Elaeis_guineensis

80 XP_008792453.1_Phoenix_dactylifera

100 XP_014660331.1_Setaria_italica

4 KQL14938.1_Setaria_italica

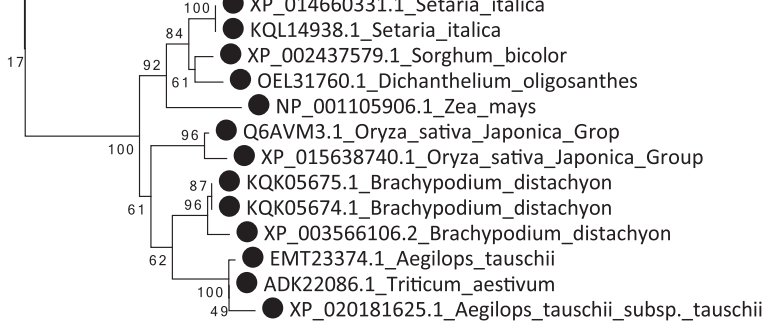

H

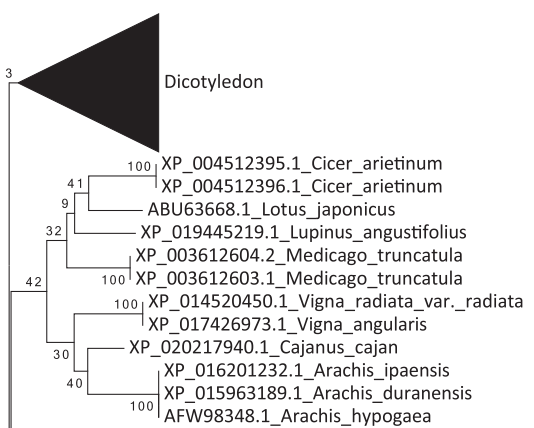

AFW98348.1_Arachis_hypogaea

JAT51841.1_Anthurium_amnicola

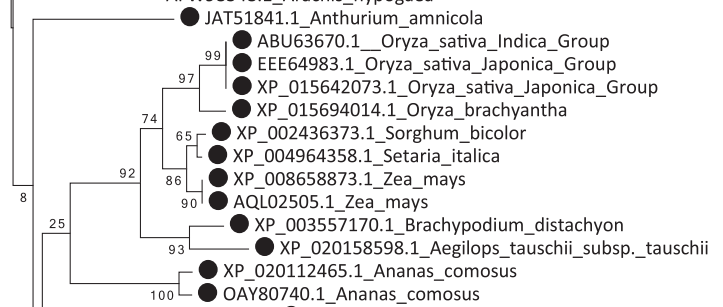

100 OAY80740.1_Ananas_comosus

93. XP_020570795.1_Phalaenopsis_equestris

XP_020570794.1_Phalaenopsis_equestris

XP 020570796.1_Phalaenopsis_equestris

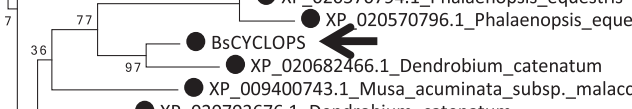

XP_020703676.1_Dendrobium_catenatum

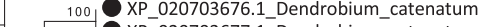

26 XP_020703677.1_Dendrobium_catenatum

100 XP_020582051.1_Phalaenopsis_equestris

XP_020242384.1_Asparagus_officinalis

$\stackrel{\longmapsto}{0.02}$

XP_017698077.1_Phoenix_dacty

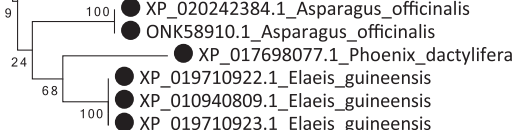

${ }_{100}$ XP_010940809.1_Elaeis_guineensis 
de novo reference assembly of $B$. striata-originated genes using BLAST software (McGinnis and Madden 2004). Orthologs of all the CSG from monocot rice (Oryza sativa) and dicot $L$. japonicus CSG (the gene ID of $O$. sativa sequences and L. japonicus sequences are listed in Supplementary Table S3) were found in B. striata (Supplementary Table S4). To examine the evolutionary relationship of the CSG in B. striata and other plant species, phylogenetic trees were constructed from alignments of their full-length protein sequences. All of the B. striata CSG were distinctly clustered into a group from monocotyledonous plants (Fig. 1; Supplementary Fig. S1). A set of CSG is also conserved in other photosynthetic orchids Phalaenopsis equestris and Dendrobium catenatum (Fig. 1).

\section{Differential regulation of $B$. striata genes between protocorm ages.}

To identify the plant genes involved in OM symbiosis, we compared the transcriptomes of the two transitional periods of symbiotic protocorms: week one versus week two (W1-W2), which mainly represents the change from the early (fungal invasion) to middle (fungal colonization) stages, and week two versus week three (W2-W3), which mainly represents the transition from the middle to late (hyphal degradation) stages. A total of 1,649 and 1,303 genes had significantly different expression levels (fold change $\geq 2.0$ or $\leq-2$, false discovery rate $[\mathrm{FDR}]<$ 0.05 ) during the $\mathrm{W} 1-\mathrm{W} 2$ and $\mathrm{W} 2-\mathrm{W} 3$ transitions, respectively (Fig. 2A; Supplementary Tables S5 and S6). Among these differentially expressed genes (DEG), 1,417 and 1,071 were altered specifically during W1-W2 and W2-W3, respectively, whereas only 232 DEG were present in both comparison sets (Fig. 2A).

To characterize these DEG, we performed a gene ontology (GO) enrichment analysis using the BLAST2GO tool (Conesa et al. 2005). After dividing DEG into four groups (W1 > W2 or $\mathrm{W} 1<\mathrm{W} 2$ groups in $\mathrm{W} 1-\mathrm{W} 2$ transition and $\mathrm{W} 2>\mathrm{W} 3$ or $\mathrm{W} 2<$ W3 groups in W2-W3 transition), the frequency of each GO term was compared between each DEG group and the de novo reference assembly of plant-originated genes. There were 85 significantly overrepresented GO terms, when redundant higher hierarchy terms were removed from the list (FDR $<0.05$ ). These GO terms were clustered into five main groups based on the FDR values (Fig. 2B). Cluster 1 contained 30 terms that were overrepresented in W1. Cluster 2 included 22 terms that had a relatively higher FDR than the others and had no particular pattern. Clusters 3 and 4 included 25 terms that were overrepresented in W2. Cluster 5 contained eight terms that were overrepresented in W3. Among these, only 14 terms (16\% in total significant GO terms) were detected more than two comparison sets (Table 1), indicating that the cellular environment of the protocorms is altered drastically throughout the three stages of OM symbiosis. Several overrepresented GO terms, as described in Table 1, particularly within the clusters 3 and 4 that show the group upregulated in W2, were shared with the GO terms that overrepresented in upregulated genes during $\mathrm{AM}$ or RL symbiosis (Handa et al. 2015). There were also no significant GO terms functionally classified as being involved in response to biotic and abiotic stimuli or specifically involved in stress response (Table 1). In total, $13 \mathrm{GO}$ terms were overrepresented in common DEG between W1-W2 and W2-W3 (Supplementary Table S7). In particular, these terms included some significantly overrepresented GO terms related to nitrogen metabolism such as "nitrate reductase activity", "nitric oxide metabolic process", and "nitric oxide biosynthetic process".

\section{Expression patterns of symbiosis-related genes at each protocorm age.}

To further characterize the expression profile of symbiotic germination, we compared our list of DEG with the National
Center for Biotechnology Information nonredundant (nr) database to assign functional annotations. We revealed that the expression of many homologs of the AM-induced genes (Handa et al. 2015) was significantly altered during symbiotic germination (Table 2). In contrast, a few types of genes related to biotic stress such as pathogenesis-related 1-like genes and defense-related WRKY genes changed their expression during W1-W2 or W2-W3 transition. Although it is well known that these genes are typical markers in defense against plant pathogens (Lu et al. 2012; Rivas 2012), no GO terms associated with biotic stress responses were identified, indicating that colonization of B. striata protocorms by Tulasnella does not trigger a strong defense response. In AM symbiosis, there are many studies of the effects of phytohormones as important regulators of AM development (Gutjahr 2014). It has been reported that gibberellin (GA) reduces hyphal colonization and arbuscule formation during AM symbiosis (Takeda et al. 2015) and auxin is positively correlated with AM colonization (Hause et al. 2007). In phytohormone-related processes resulting from our study, the expression of a GA biosynthesis gene encoding GA 20 oxidase 1-D-like (GA20ox) was downregulated in W2 relative to W1 (Table 2). Conversely, a gene encoding a GAinactivating enzyme, GA 2- $\beta$-dioxygenase-like (GA2ox), was upregulated in W2 relative to W3 (Table 2). Auxin-responsive genes were upregulated in W2: genes encoding the auxinresponsive protein SAUR32-like and auxin transporter-like protein 3 were highly expressed in $\mathrm{W} 2$ relative to $\mathrm{W} 1$, and genes encoding the auxin-induced protein 6B-like and auxinresponsive protein SAUR50-like were upregulated in W2 relative to W3. We also identified 17 transporter genes related to nitrogen and sugar transfer showing increased expression during symbiotic germination (Table 2), which corresponds to previous studies on OM symbioses (Fochi et al. 2017; Perotto et al. 2014; Suetsugu et al. 2017; Zhao et al. 2014).

\section{Functional complementation of the $L$. japonicus ccamk mutant using $B$. striata $C C a M K$.}

Although we identified a set of CSG in B. striata genome and found some common features of AM symbiosis, the functional conservation of these genes is yet to be elucidated. It was previously reported that one of the CSG, $C C A M K$, is necessary not only for AM and RL symbiosis but also for actinorhizal symbiosis (Svistoonoff et al. 2013), which suggests that $C C a M K$ could play a key role in the coordination of the symbiotic infection processes. Actually, CCAMK is one of the most frequently investigated genes in previous studies that have examined CSG functional conservation (Banba et al. 2008; Chen et al. 2007; Godfroy et al. 2006). Previous studies reported that O. sativa CCaMK (OsCCaMK) rescued the defective nodulation phenotype of the ccamk mutant in L. japonicus, resulting in the formation of mature nodules (Banba et al. 2008). Therefore, we examined the potential function of $B$. striata $C C A M K$ $(B s C C a M K)$. A homology search showed that $B s C C a M K$ is a single-copy gene in B. striata as it is in rice, L. japonicus, and Medicago truncatula, and that it possesses the functional domains required for mutual symbiosis (Takeda et al. 2012) (Supplementary Fig. S2). In addition, the expression of $B s C C a M K$ increased during symbiotic germination. We next tested whether BsCCaMK possesses the capability of forming both AM and RL symbiosis, instead of an L. japonicus CCaMK, by performing a cross-species complementation assay of the $L$. japonicus ccamk-3 mutant (Tirichine et al. 2006) with BsCCaMK. The cDNA of BsCCaMK under the control of the L. japonicus UBIQUITIN1 (UBQ1) promoter (Maekawa et al. 2008) was introduced into ccamk-3. Upon inoculating with Rhizophagus irregularis, a general species of AM fungi, intracellular symbiosis of AM fungi was fully restored in transgenic ccamk-3 
roots carrying $B s C C a M K$ (ccamk-3/BsCCaMK), as well as those transformed with $L j C C a M K$ (ccamk-3/LjCCaMK) (Fig. 3A). Moreover, in response to DsRed-labeled Mesorhizobium loti, a compatible rhizobial bacterium of Lotus spp., nodule formation was fully restored on the roots of both ccamk-3/BsCCaMK and ccamk-3/LjCCaMK, (Fig. 3B). These results demonstrate that BsCCaMK conserves the property of forming both AM and RL symbiosis in L. japonicus.

\section{Induction of AM symbiosis marker homologs in symbiotic protocorms.}

To further explore the presence of molecular systems common to AM plants, we examined the expression of $B$. striata homologs of AM-specific marker genes identified in rice (Gutjahr et al. 2008). We searched for 17 of these rice AM marker genes in the $B$. striata reference sequence using the BLASTX tool, identifying 12 conserved homologs in $B$. striata with sufficiently low E values (E value < 1.0E-05; Supplementary Table S8). Quantitative reverse-transcription polymerase chain reaction (RT-PCR) was conducted for nine randomly selected homolog genes in symbiotic protocorms sampled weekly for 3 weeks, including at the start of the experiment. The expression of eight genes (BsAM1, BsAM2, BsAM11, BsAM14, BsAM20, BsAM25, BsAM34, and $B s A M 39$ ) significantly increased during symbiotic germination, whereas the expression of BsAM18 decreased (Fig. 4). We then refer to these eight genes as OM marker genes.

To examine whether the activation of these OM marker genes occurred in relation to symbiosis, the same expression analysis was performed using protocorms growing on a sucrosecontaining medium with Tulasnella. Generally, OM relationships are unstable; symbiotic fungi could potentially become pathogenic parasites or fail to colonize the protocorms when the temperature or carbon source is not suitable for symbiosis (Beyrle et al. 1995; Harvais and Hadley 1967). On the sucrosecontaining medium, we found serendipitously that $B$. striata protocorms having symbiosis with Tulasnella contained significantly lower numbers of symbiotic cells with the destruction of the peloton structure, whereas hyphal growth in axenic culture was unaltered with the additional sucrose (Supplementary Fig. S3). Quantitative RT-PCR was conducted for the aberrant symbiotic protocorms sampled every week from germination to week three. The expression of BsAM20 and BsAM39 were significantly lower when compared with those in the normal medium (Fig. 4). BsAM25 and BsAM34 transcripts were not detected as germination progressed on the sucrose-containing medium, unlike in the expression on the normal medium (Fig. 4).

Gutjahr et al. (2008) reported that a few AM marker genes in rice are expressed in arbusculated cells or in cortical cells flanking intercellularly growing hyphae, suggesting the existence of cell-autonomous signaling events operating selectively in certain cell types during colonization by the AM fungus. In symbiotic protocorms, pelotons are limited to cortical cells and are not found in the apical meristem (Shimura and Koda 2005). To confirm the association between the expression of OM marker genes and the localization of the fungus in the protocorms, we compared their expression in the two halves of the protocorm using quantitative RT-PCR. The top half of the protocorm is likely to contain few or no hyphae, whereas numerous pelotons are observed in the bottom half (Supplementary Fig. S4). Tulasnella mRNA encoding a translation elongation factor $(T E F)$, which was identified from a search against the assembled genome scaffolds of Tulasnella using Piriformospora indica TEF (GenBank accession number AJ249912.1) as a query sequence, was approximately 3.1 times more abundant in the bottom half of the protocorm than the top half. Similarly, the expression levels of the eight OM marker genes (BsAM1, BsAM2, BsAM11, BsAM14, $B s A M 20, B s A M 25, B s A M 34$, and $B s A M 39$ ) were 1.7 to 73.2 times higher in the bottom half than the top. In contrast, BsAM18, which was omitted from OM marker genes, had significantly lower expression in the bottom than the top half. These results were congruent with the notion that the expression of the eight $\mathrm{OM}$ marker genes is associated with the presence of the fungus, although the top and bottom halves of the protocorm are likely to differ in many other traits as well.

\section{DISCUSSION}

CSG are essential components of the symbiosis signaling pathway, required for the establishment of mutual symbioses with both AM fungi and rhizobia. In this study, we performed
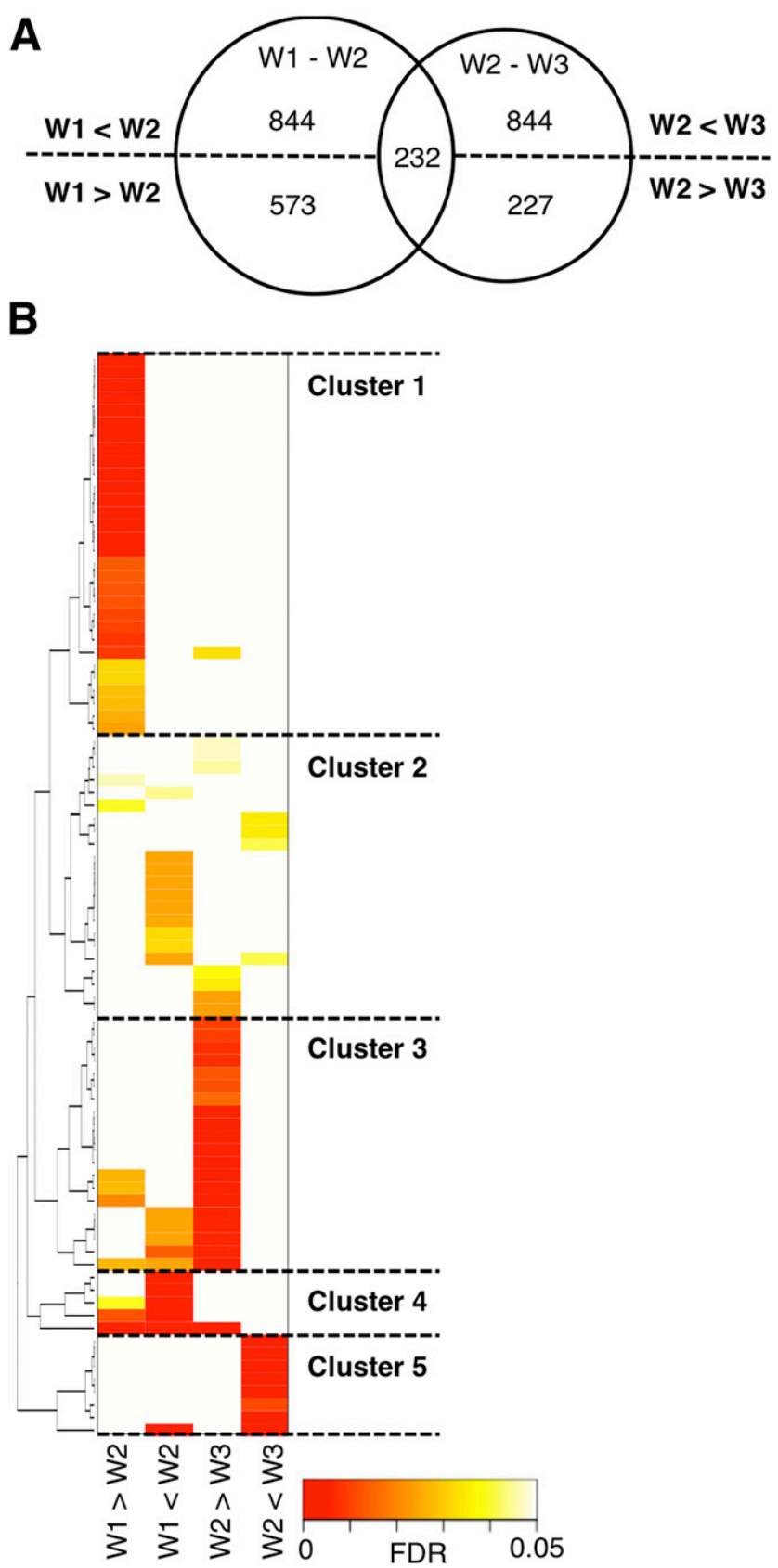

Fig. 2. Bletilla striata gene transcription during symbiotic germination. A, Venn diagram showing the number of differentially expressed genes (DEG) between transitions week one versus week two (W1-W2) and week two versus week three (W2-W3). B, Gene ontology (GO) enrichment analysis of DEG in the de novo reference assembly. Heatmaps were generated using the heatmap. 2 function in the gplots $\mathrm{R}$ package. Hierarchical clustering was performed on the false discovery rate (FDR) values associated with each GO term. 
Table 1. Significantly overrepresented gene ontology (GO) terms during the symbiotic germination of Bletilla striata inoculated with Tulasnella sp. strain HR1-1

\begin{tabular}{|c|c|c|c|c|c|}
\hline \multirow[b]{2}{*}{$\operatorname{Code}^{b}$} & \multirow[b]{2}{*}{ Term } & \multicolumn{4}{|c|}{ False discovery rate ra $^{a}$} \\
\hline & & $\mathbf{W 1}>\mathbf{W 2}$ & $\mathbf{W} 1<\mathrm{W} 2$ & $\mathbf{W} 2>\mathbf{W 3}$ & $\mathbf{W} 2<\mathrm{W} 3$ \\
\hline \multicolumn{6}{|l|}{ Cluster 1} \\
\hline \multicolumn{6}{|l|}{ Cellular component } \\
\hline GO:0000786 & Nucleosome & 2.03E-12 (16/61) & $\ldots$ & $\ldots$ & $\ldots$ \\
\hline GO:0009522 & Photosystem I & $1.10 \mathrm{E}-03(7 / 56)$ & $\ldots$ & $\ldots$ & $\ldots$ \\
\hline GO:0031305 & $\begin{array}{l}\text { Integral component of mitochondrial } \\
\text { inner membrane }\end{array}$ & 4.46E-03 (3/4) & $\ldots$ & $\ldots$ & $\ldots$ \\
\hline GO:0009654 & Photosystem II oxygen evolving complex & $4.98 \mathrm{E}-03(5 / 31)$ & $\ldots$ & $\ldots$ & $\ldots$ \\
\hline GO:0005618 & Cell wall & $1.35 \mathrm{E}-02(8 / 126)$ & $\ldots$ & $\ldots$ & $\ldots$ \\
\hline GO:0009535 & Chloroplast thylakoid membrane & $8.16 \mathrm{E}-03(8 / 114)$ & $\ldots$ & $\ldots$ & $\ldots$ \\
\hline \multicolumn{6}{|c|}{ Molecular function } \\
\hline • GO:0046982 & Protein heterodimerization activity & $5.06 \mathrm{E}-11(16 / 79)$ & $\ldots$ & $\ldots$ & $\ldots$ \\
\hline GO:0004170 & dUTP diphosphatase activity & $6.77 \mathrm{E}-06(4 / 0)$ & $\ldots$ & $\ldots$ & $\ldots$ \\
\hline GO:0003677 & DNA binding & $7.59 \mathrm{E}-05(42 / 1,441)$ & $\ldots$ & $\ldots$ & $\ldots$ \\
\hline GO:0004612 & $\begin{array}{l}\text { Phosphoenolpyruvate carboxykinase } \\
\text { (ATP) activity }\end{array}$ & $2.55 \mathrm{E}-04(3 / 0)$ & $\ldots$ & $\ldots$ & $\ldots$ \\
\hline O GO:0016984 & $\begin{array}{l}\text { Ribulose-bisphosphate carboxylase } \\
\text { activity }\end{array}$ & $1.74 \mathrm{E}-03(3 / 2)$ & $\ldots$ & $\ldots$ & $\ldots$ \\
\hline GO:0008234 & Cysteine-type peptidase activity & $4.03 \mathrm{E}-03(7 / 73)$ & $\ldots$ & $\ldots$ & $\ldots$ \\
\hline GO:0016702 & $\begin{array}{l}\text { Oxidoreductase activity, acting on single } \\
\text { donors with incorporation of molecular } \\
\text { oxygen, incorporation of two atoms of } \\
\text { oxygen }\end{array}$ & 3.73E-03 (6/48) & $\cdots$ & $\cdots$ & $\cdots$ \\
\hline GO:0016168 & Chlorophyll binding & $3.08 \mathrm{E}-03(6 / 46)$ & $\ldots$ & $\ldots$ & $\ldots$ \\
\hline GO:0015266 & Protein channel activity & $1.26 \mathrm{E}-02(3 / 7)$ & $\ldots$ & $\ldots$ & $\ldots$ \\
\hline GO:0010333 & Terpene synthase activity & $8.89 \mathrm{E}-03(4 / 18)$ & $\ldots$ & 3.31E-02 (3/19) & $\ldots$ \\
\hline GO:0046872 & Metal ion binding & $2.78 \mathrm{E}-02(64 / 3,463)$ & $\ldots$ & $\ldots$ & $\ldots$ \\
\hline GO:0008974 & Phosphoribulokinase activity & $2.43 \mathrm{E}-02(2 / 1)$ & $\ldots$ & $\ldots$ & $\ldots$ \\
\hline \multicolumn{6}{|c|}{ Biological process } \\
\hline GO:0046081 & dUTP catabolic process & $2.55 \mathrm{E}-04(3 / 0)$ & $\ldots$ & $\ldots$ & $\ldots$ \\
\hline GO:0006226 & dUMP biosynthetic process & $2.55 \mathrm{E}-04(3 / 0)$ & $\ldots$ & $\ldots$ & $\ldots$ \\
\hline GO:0019253 & Reductive pentose-phosphate cycle & $7.85 \mathrm{E}-04(3 / 1)$ & $\ldots$ & $\ldots$ & $\ldots$ \\
\hline GO:0009853 & Photorespiration & $4.46 \mathrm{E}-03(3 / 4)$ & $\ldots$ & $\ldots$ & $\ldots$ \\
\hline GO:0006334 & Nucleosome assembly & $1.35 \mathrm{E}-02(5 / 41)$ & $\ldots$ & $\ldots$ & $\ldots$ \\
\hline GO:0009765 & Photosynthesis, light harvesting & $1.26 \mathrm{E}-02(5 / 40)$ & $\ldots$ & $\ldots$ & $\ldots$ \\
\hline GO:0006260 & DNA replication & $1.07 \mathrm{E}-02(7 / 89)$ & $\ldots$ & $\ldots$ & $\ldots$ \\
\hline GO:0009647 & Skotomorphogenesis & $1.01 \mathrm{E}-02(2 / 0)$ & $\ldots$ & $\ldots$ & $\ldots$ \\
\hline GO:0018298 & Protein-chromophore linkage & $3.17 \mathrm{E}-02(5 / 53)$ & $\ldots$ & $\ldots$ & $\ldots$ \\
\hline GO:0005976 & Polysaccharide metabolic process & $3.17 \mathrm{E}-02(11 / 272)$ & $\ldots$ & $\ldots$ & $\ldots$ \\
\hline GO:0006094 & Gluconeogenesis & $2.85 \mathrm{E}-02(3 / 11)$ & $\ldots$ & $\ldots$ & $\ldots$ \\
\hline GO:0071555 & Cell wall organization & $2.58 \mathrm{E}-02(9 / 180)$ & $\ldots$ & $\ldots$ & $\ldots$ \\
\hline \multicolumn{6}{|c|}{ Cluster 2} \\
\hline \multicolumn{6}{|l|}{ Cellular component } \\
\hline O GO:0042719 & $\begin{array}{l}\text { Mitochondrial intermembrane space } \\
\text { protein transporter complex }\end{array}$ & $\ldots$ & $2.45 \mathrm{E}-02(2 / 0)$ & $\ldots$ & $\ldots$ \\
\hline - GO:0016021 & Integral component of membrane & $\ldots$ & 2.45E-02 $(123 / 5,487)$ & $\ldots$ & 4.14E-02 $(120 / 5,490)$ \\
\hline \multicolumn{6}{|c|}{ Molecular function } \\
\hline GO:0003852 & 2-Isopropylmalate synthase activity & $\ldots$ & $\ldots$ & 4.72E-02(2/4) & $\ldots$ \\
\hline GO:0004601 & Peroxidase activity & & $\ldots$ & $4.55 \mathrm{E}-02(5 / 99)$ & $\ldots$ \\
\hline GO:0016630 & Protochlorophyllide reductase activity & $3.94 \mathrm{E}-02(2 / 2)$ & $\ldots$ & $\ldots$ & \\
\hline GO:0003983 & $\begin{array}{l}\text { UTP:glucose-1-phosphate } \\
\text { uridylyltransferase activity }\end{array}$ & ... & $\ldots$ & $\ldots$ & $3.48 \mathrm{E}-02(2 / 0)$ \\
\hline O GO:0033743 & $\begin{array}{l}\text { Peptide-methionine (R)-S-oxide } \\
\text { reductase activity }\end{array}$ & $\ldots$ & $\ldots$ & $\ldots$ & 4.14E-02 (3/6) \\
\hline O GO:0009815 & $\begin{array}{l}\text { 1-Aminocyclopropane-1-carboxylate } \\
\text { oxidase activity }\end{array}$ & $\ldots$ & $2.45 \mathrm{E}-02(2 / 0)$ & $\ldots$ & $\ldots$ \\
\hline O GO:0010309 & $\begin{array}{l}\text { Acireductone dioxygenase [iron(II)- } \\
\text { requiring] activity }\end{array}$ & $\ldots$ & $2.45 \mathrm{E}-02(3 / 5)$ & $\ldots$ & $\ldots$ \\
\hline GO:0017153 & Sodium:dicarboxylate symporter activity & $\ldots$ & $2.45 \mathrm{E}-02(2 / 0)$ & $\ldots$ & $\ldots$ \\
\hline GO:0004553 & $\begin{array}{l}\text { Hydrolase activity, hydrolyzing O- } \\
\text { glycosyl compounds }\end{array}$ & $\cdots$ & $2.53 \mathrm{E}-02(20 / 490)$ & $\cdots$ & $\cdots$ \\
\hline GO:0008171 & O-methyltransferase activity & $\ldots$ & $3.22 \mathrm{E}-02(6 / 53)$ & $\ldots$ & $\ldots$ \\
\hline GO:0016788 & Hydrolase activity, acting on ester bonds & $\ldots$ & $\ldots$ & $3.74 \mathrm{E}-02(14 / 747)$ & $\ldots$ \\
\hline GO:0008977 & $\begin{array}{l}\text { Prephenate dehydrogenase (NAD+) } \\
\text { activity }\end{array}$ & $\cdots$ & $\ldots$ & $2.40 \mathrm{E}-02(2 / 2)$ & $\ldots$ \\
\hline ○ GO:0004665 & $\begin{array}{l}\text { Prephenate dehydrogenase (NADP+) } \\
\text { activity }\end{array}$ & $\ldots$ & $\ldots$ & $2.40 \mathrm{E}-02(2 / 2)$ & $\ldots$ \\
\hline
\end{tabular}

\footnotetext{
${ }^{a}$ Numbers in parentheses represent differentially expressed gene counts/reference counts.

${ }^{b}$ Black (filled) circles represent the GO terms shared with the terms that were overrepresented in upregulated genes during arbuscular mycorrhizal or rhizobium-legume symbioses reported by Handa et al. (2015).
} 
transcriptome sequencing and de novo assembly of B. striata, which is an initially mycoheterotrophic and non-AM plant, under symbiotic conditions, and analyzed the sequence and functional conservation of CSG in B. striata.
Many orchids have recruited the polyphyletic Rhizoctonia fungi in the evolution of mycorrhizal associations (Martos et al. 2009; Ogura-Tsujita et al. 2009; Rasmussen and Rasmussen 2007; Selosse and Martos 2014). Many of these fungi have a

Table 1. (Continued from previous page)

\begin{tabular}{|c|c|c|c|c|c|}
\hline \multirow[b]{2}{*}{ Code $^{b}$} & \multirow[b]{2}{*}{ Term } & \multicolumn{4}{|c|}{ False discovery rate ${ }^{a}$} \\
\hline & & $\mathrm{W} 1>\mathrm{W} 2$ & $\mathrm{~W} 1<\mathrm{W} 2$ & $\mathrm{~W} 2>\mathrm{W3}$ & $\mathbf{W 2}<\mathrm{W3}$ \\
\hline \multicolumn{6}{|l|}{ Biological process } \\
\hline GO:0006571 & Tyrosine biosynthetic process & & $\ldots$ & 4.72E-02 (2/4) & $\ldots$ \\
\hline GO:0031408 & Oxylipin biosynthetic process & $4.66 \mathrm{E}-02(3 / 14)$ & $\ldots$ & $\ldots$ & $\ldots$ \\
\hline GO:0045454 & Cell redox homeostasis & $\ldots$ & $4.46 \mathrm{E}-02(8 / 106)$ & $\ldots$ & $\ldots$ \\
\hline GO:0006011 & UDP-glucose metabolic process & $\ldots$ & $\ldots$ & $\ldots$ & $3.48 \mathrm{E}-02(2 / 0)$ \\
\hline GO:0045039 & $\begin{array}{l}\text { Protein import into mitochondrial inner } \\
\text { membrane }\end{array}$ & $\cdots$ & $2.45 \mathrm{E}-02(2 / 0)$ & $\cdots$ & $\ldots$ \\
\hline GO:0015711 & Organic anion transport & $\ldots$ & $3.22 \mathrm{E}-02(9 / 127)$ & $\ldots$ & $\ldots$ \\
\hline GO:0042128 & Nitrate assimilation & $\ldots$ & $\ldots$ & $3.48 \mathrm{E}-02(2 / 3)$ & $\ldots$ \\
\hline \multicolumn{6}{|l|}{ Cluster 3} \\
\hline \multicolumn{6}{|l|}{ Cellular component } \\
\hline GO:0009505 & Plant-type cell wall & $\ldots$ & $\ldots$ & $1.01 \mathrm{E}-02(4 / 32)$ & $\ldots$ \\
\hline GO:0031225 & Anchored component of membrane & $\ldots$ & $\ldots$ & $1.61 \mathrm{E}-02(4 / 38)$ & $\ldots$ \\
\hline GO:0005576 & Extracellular region & 2.70E-02 (12/307) & $\ldots$ & $1.70 \mathrm{E}-03(11 / 308)$ & $\ldots$ \\
\hline \multicolumn{6}{|c|}{ Molecular function } \\
\hline GO:0016620 & $\begin{array}{l}\text { Oxidoreductase activity, acting on the } \\
\text { aldehyde or oxo group of donors, NAD } \\
\text { or NADP as acceptor }\end{array}$ & $\cdots$ & $\cdots$ & $9.72 \mathrm{E}-03(5 / 63)$ & $\cdots$ \\
\hline GO:0045548 & Phenylalanine ammonia-lyase activity & $\ldots$ & $\ldots$ & 7.24E-03 (3/9) & $\ldots$ \\
\hline GO:0003866 & $\begin{array}{l}\text { 3-Phosphoshikimate } 1 \text { - } \\
\text { carboxyvinyltransferase activity }\end{array}$ & $\cdots$ & $\cdots$ & $2.98 \mathrm{E}-04(3 / 1)$ & $\cdots$ \\
\hline GO:0016705 & $\begin{array}{l}\text { Oxidoreductase activity, acting on paired } \\
\text { donors, with incorporation or reduction } \\
\text { of molecular oxygen }\end{array}$ & $\cdots$ & $\cdots$ & 4.24E-05 (13/294) & $\cdots$ \\
\hline GO:0005506 & Iron ion binding & $\ldots$ & $\ldots$ & 3.30E-05 (13/286) & $\ldots$ \\
\hline GO:0004497 & Monooxygenase activity & 2.78E-02 (10/223) & $\ldots$ & $2.85 \mathrm{E}-06(13 / 220)$ & $\ldots$ \\
\hline GO:0043546 & Molybdopterin cofactor binding & $\ldots$ & $2.45 \mathrm{E}-02(2 / 0)$ & $6.00 \mathrm{E}-03(2 / 0)$ & $\ldots$ \\
\hline GO:0050464 & Nitrate reductase (NADPH) activity & $\ldots$ & $2.45 \mathrm{E}-02(2 / 0)$ & $6.00 \mathrm{E}-03(2 / 0)$ & $\ldots$ \\
\hline GO:0043531 & ADP binding & $\ldots$ & $1.41 \mathrm{E}-02(5 / 25)$ & $6.00 \mathrm{E}-03(4 / 26)$ & $\ldots$ \\
\hline GO:0020037 & Heme binding & 2.73E-02 (12/308) & $2.45 \mathrm{E}-02(15 / 305)$ & $2.58 \mathrm{E}-10(20 / 300)$ & $\ldots$ \\
\hline \multicolumn{6}{|l|}{ Biological process } \\
\hline GO:0009800 & Cinnamic acid biosynthetic process & $\ldots$ & $\ldots$ & 7.24E-03 (3/9) & $\ldots$ \\
\hline GO:0006559 & L-phenylalanine catabolic process & $\ldots$ & $\ldots$ & $1.28 \mathrm{E}-02(3 / 12)$ & $\ldots$ \\
\hline GO:0016049 & Cell growth & $\ldots$ & $\ldots$ & $1.21 \mathrm{E}-02(4 / 34)$ & $\ldots$ \\
\hline GO:0010215 & Cellulose microfibril organization & $\ldots$ & $\ldots$ & $5.21 \mathrm{E}-04(4 / 11)$ & $\ldots$ \\
\hline GO:0009423 & Chorismate biosynthetic process & $\ldots$ & $\ldots$ & $1.81 \mathrm{E}-03(3 / 4)$ & $\ldots$ \\
\hline GO:0042744 & Hydrogen peroxide catabolic process & $2.06 \mathrm{E}-02(5 / 46)$ & $\ldots$ & $3.56 \mathrm{E}-03(5 / 46)$ & $\ldots$ \\
\hline GO:0006809 & Nitric oxide biosynthetic process & $\ldots$ & $2.45 \mathrm{E}-02(2 / 0)$ & $6.00 \mathrm{E}-03(2 / 0)$ & $\ldots$ \\
\hline \multicolumn{6}{|l|}{ Cluster 4} \\
\hline \multicolumn{6}{|l|}{ Cellular component } \\
\hline GO:0005744 & $\begin{array}{l}\text { Mitochondrial inner membrane } \\
\text { presequence } \\
\text { translocase complex }\end{array}$ & $1.26 \mathrm{E}-02(3 / 7)$ & $3.81 \mathrm{E}-03(4 / 6)$ & $\cdots$ & $\cdots$ \\
\hline \multicolumn{6}{|l|}{ Molecular function } \\
\hline GO:0015035 & Protein disulfide oxidoreductase activity & $\ldots$ & $5.80 \mathrm{E}-03(8 / 66)$ & $\ldots$ & $\ldots$ \\
\hline \multicolumn{6}{|l|}{ Biological process } \\
\hline GO:0006662 & Glycerol ether metabolic process & $\ldots$ & 1.17E-03 (7/32) & $\ldots$ & $\ldots$ \\
\hline GO:0030150 & Protein import into mitochondrial matrix & $3.94 \mathrm{E}-02(3 / 13)$ & $8.16 \mathrm{E}-05(6 / 10)$ & $\ldots$ & $\ldots$ \\
\hline GO:0055114 & Oxidation-reduction process & $2.31 \mathrm{E}-03(45 / 1,911)$ & $1.46 \mathrm{E}-03(59 / 1,897)$ & 4.05E-08 (41/1,915) & $\ldots$ \\
\hline \multicolumn{6}{|l|}{ Cluster 5} \\
\hline \multicolumn{6}{|l|}{ Cellular component } \\
\hline GO:0005634 & Nucleus & $\ldots$ & $\ldots$ & $\ldots$ & $1.13 \mathrm{E}-04(69 / 2,278)$ \\
\hline \multicolumn{6}{|l|}{ Molecular function } \\
\hline GO:0043565 & Sequence-specific DNA binding & $\ldots$ & $\ldots$ & $\ldots$ & 3.68E-05 (19/268) \\
\hline GO:0051087 & Chaperone binding & $\ldots$ & $\ldots$ & $\ldots$ & $2.27 \mathrm{E}-07(10 / 33)$ \\
\hline GO:0001406 & $\begin{array}{l}\text { Glycerophosphodiester transmembrane } \\
\text { transporter activity }\end{array}$ & $\cdots$ & $\ldots$ & $\ldots$ & $2.70 \mathrm{E}-03(3 / 1)$ \\
\hline GO:0005509 & Calcium ion binding & $\ldots$ & $\ldots$ & $\ldots$ & $1.10 \mathrm{E}-02(16 / 310)$ \\
\hline GO:0000981 & $\begin{array}{l}\text { RNA polymerase II transcription factor } \\
\text { activity, sequence-specific DNA } \\
\text { binding }\end{array}$ & $\cdots$ & $\cdots$ & $\cdots$ & $5.82 \mathrm{E}-03(8 / 71)$ \\
\hline \multicolumn{6}{|l|}{ Biological process } \\
\hline GO:0001407 & $\begin{array}{l}\text { Glycerophosphodiester transmembrane } \\
\text { transport }\end{array}$ & $\cdots$ & $\cdots$ & $\ldots$ & $2.70 \mathrm{E}-03(3 / 1)$ \\
\hline GO:0006355 & $\begin{array}{l}\text { Regulation of transcription, DNA- } \\
\text { templated }\end{array}$ & $\ldots$ & $3.81 \mathrm{E}-03(38 / 1,064)$ & $\cdots$ & $1.96 \mathrm{E}-17(67 / 1035)$ \\
\hline
\end{tabular}


free-living, saprotrophic stage but may also have an endophytic stage without apparent infection symptoms (Selosse et al. 2009; van der Heijden et al. 2015; Weiß et al. 2016). It has been suggested that there are two trajectories for the recruiting of the mycorrhizal fungi: the mycorrhizal association evolved directly from soil saprotrophic ancestors or indirectly through endophytic ancestors (Selosse et al. 2018). Recruiting these fungi as symbiotic partners may induce the need to cope with problems such as the fungi secreting a variety of cell-wall-degrading enzymes that could induce plant immunity (Floudas et al. 2012; Juge 2006). Actually, hydrolytic enzymes involved in cell wall degradation abound in an orchid mycorrhizal fungus, Tulasnella calospora (Lahrmann et al. 2015), which shows the highest identity with the Tulasnella strain used in this study. However, although B. striata can form mycorrhizal associations with saprotrophic fungi (Masuhara and Katsuya 1989; Yamamoto et al. 2017), which have the potential to elicit strong defense responses in plants, our transcriptome data provided no evidence of strong defense activation at the GO level in $B$. striata during symbiotic germination. This is similar to the results of other transcriptome studies of orchids (Perotto et al. 2014; Suetsugu et al. 2017). On the fungal side, it is possible that OM fungi can produce molecules that suppress plant defense responses, such as the secreted protein 7 in $R$. irregularis and Laccaria bicolor (Kloppholz et al. 2011; Plett et al. 2014). On the plant side, these findings suggest that $B$. striata recruits a signaling pathway to exploit saprotrophic fungi without inducing a significant stress response. In this study, we revealed that $B$. striata possesses all of the CSG previously identified in other plant species. One of the genes, $B s C C a M K$, had highly conserved functional domains of $C C a M K$ and complemented the function of LjCCaMK. Moreover, B. striata possesses 12 genes that are highly similar to the AM marker genes in rice (Gutjahr et al. 2008). In all, 8 of 12 homolog genes (BsAM1, BsAM2, BsAM11, BsAM14, BsAM20, BsAM25, BsAM34, and $B s A M 39)$ were significantly induced during mycoheterotrophic

Table 2. M-induced, phytohormone-related, and transporter genes that are differentially expressed in Bletilla striata protocorms associated with Tulasnella sp. strain HR1-1

\begin{tabular}{|c|c|c|c|}
\hline Annotation $^{\mathrm{a}}$ & Sequence ID & Fold change $^{b}$ & FDR $^{\mathrm{c}}$ \\
\hline \multicolumn{4}{|l|}{ W1-W2 } \\
\hline Ammonium transporter 3 member 1-like & DN38547_c0_g2_i1::g.160833::m.160833 & 1.19 & 4.40E-02 \\
\hline Ankyrin repeat domain-containing 65 -like & DN19080_c0_g1_i1::g.64529::m.64529 & 1.57 & $3.19 \mathrm{E}-03$ \\
\hline Ankyrin repeat-containing At3g 12360 -like & DN24832 c0 g1 il ::g.8235::m.8235 & 1.03 & $3.86 \mathrm{E}-02$ \\
\hline Blue copper -like & DN149578_c0_g1_i1::g.6945::m.6945 & -1.69 & 3.97E-04 \\
\hline Chitinase 4-like & DN50382_c0_g1_i2::g.195442::m.195442 & -1.07 & $2.68 \mathrm{E}-02$ \\
\hline GDSL esterase lipase At 1 g28570-like & DN102229_c0_g2_i1::g.7228::m.7228 & -2.08 & $4.86 \mathrm{E}-03$ \\
\hline GDSL esterase lipase At1g74460-like & DN59482_c0_g5_i1::g.120683::m.120683 & -2.41 & $5.64 \mathrm{E}-10$ \\
\hline GDSL esterase lipase At2g23540-like & DN43229_c0_g1_i1::g.140659::m.140659 & 2.20 & $6.23 \mathrm{E}-04$ \\
\hline GDSL esterase lipase At3g48460 & DN43208_c0_g1_i1::g.140713::m.140713 & -1.21 & $9.76 \mathrm{E}-03$ \\
\hline GDSL esterase lipase At5g33370-like & DN151092_c0_g1_i1::g.1602::m.1602 & 1.20 & $2.84 \mathrm{E}-03$ \\
\hline GDSL esterase lipase At5g55050-like & DN42230_c0_g1_i1 ::g.154911::m.154911 & 5.45 & $9.67 \mathrm{E}-04$ \\
\hline GDSL esterase lipase At5g55050-like & DN42230_c0_g1_i2::g.154912::m.154912 & 5.63 & $2.66 \mathrm{E}-04$ \\
\hline GDSL esterase lipase At5g55050-like & DN42230_c0_g1_i3::g.154913::m.154913 & 4.87 & $1.07 \mathrm{E}-02$ \\
\hline GDSL esterase lipase EXL3-like & DN60397_c1_g6_i11::g.14051::m.14051 & 2.31 & $2.83 \mathrm{E}-06$ \\
\hline GDSL esterase lipase EXL3-like & DN134368_c0_g1_i1::g.52::m.52 & -1.31 & $3.86 \mathrm{E}-02$ \\
\hline Germin 3-8 & DN45919_c0_g1_i1::g.205096::m.205096 & -1.40 & $8.40 \mathrm{E}-03$ \\
\hline Germin 9-3 & DN48078_c0_g2_i1::g.60695::m.60695 & -1.32 & $1.69 \mathrm{E}-02$ \\
\hline Glutathione S-transferase & DN52467_c0_g1_i1::g.80511::m.80511 & 1.86 & 3.77E-02 \\
\hline Glycerol-3-phosphate acyltransferase 1-like & DN12938_c0_g1_i1::g.205235::m.205235 & -1.05 & $1.89 \mathrm{E}-02$ \\
\hline Glycerol-3-phosphate acyltransferase 1-like & DN60213_c7_g1_i1::g.179685::m.179685 & -1.05 & $5.34 \mathrm{E}-04$ \\
\hline Late embryogenesis abundant 2-like & DN9192_c0_g2_i1::g.240541::m.240541 & -3.31 & $9.34 \mathrm{E}-32$ \\
\hline Scarecrow 28 & DN48117_c0_g1̄i1::g.86946::m.86946 & -1.27 & $1.73 \mathrm{E}-03$ \\
\hline Subtilisin-like protease & DN1702_c0_g1_i1::g.35886::m.35886 & -1.75 & $1.54 \mathrm{E}-05$ \\
\hline Subtilisin-like protease & DN47520_c0_g1_i1::g.113202::m.113202 & 7.83 & $1.01 \mathrm{E}-14$ \\
\hline Subtilisin-like protease & DN47520_c0_g1_i2::g.113207::m.113207 & 5.10 & 4.99E-02 \\
\hline Subtilisin-like protease & DN47520_c0_g1_i3::g.113208::m.113208 & 5.56 & $4.53 \mathrm{E}-17$ \\
\hline Subtilisin-like protease & DN53912_c0_g1_i1::g.26558::m.26558 & 5.73 & $2.71 \mathrm{E}-11$ \\
\hline Subtilisin-like protease & DN64239_c0_g1_i1::g.131610::m.131610 & 5.97 & $2.29 \mathrm{E}-02$ \\
\hline Subtilisin-like protease & DN110003_c0_g1_i1::g.466::m.466 & 5.91 & $1.89 \mathrm{E}-03$ \\
\hline Subtilisin-like protease & DN158370_c0_g1_i1::g.2192::m.2192 & 5.24 & $2.05 \mathrm{E}-02$ \\
\hline Triacylglycerol lipase 2-like & DN38290_c0_g1_i1 $1:: g .63807:: m .63807$ & 1.43 & $2.96 \mathrm{E}-07$ \\
\hline Gibberellin 20 oxidase 1-D-like & DN57018_c0_g1_i1::g.134402::m.134402 & -1.23 & $2.61 \mathrm{E}-02$ \\
\hline Gibberellin 20 oxidase 1-D-like & DN57018_c0_g2_i1::g.134405::m.134405 & -1.26 & $4.54 \mathrm{E}-02$ \\
\hline Gibberellin-regulated 1-like & DN44665_c0_g1_i1::g.59936::m.59936 & 2.38 & 3.83E-06 \\
\hline Gibberellin-regulated 1-like & DN148681_c0_g1_i1::g.2046::m.2046 & 2.75 & $2.72 \mathrm{E}-07$ \\
\hline Gibberellin-regulated 9-like & DN34062_c0_g1_i1 ::g.191199::m.191199 & 2.10 & $1.43 \mathrm{E}-03$ \\
\hline Auxin-responsive SAUR32-like & DN10126_c0_g1_i1::g.126638::m.126638 & 1.31 & 4.75E-04 \\
\hline Auxin transporter 3 & DN50840_c0_g2_i1::g.61019::m.61019 & 1.13 & $1.61 \mathrm{E}-03$ \\
\hline Ammonium transporter 3 member 1-like & DN38547_c0_g2_i1::g.160833::m.160833 & 1.19 & $4.40 \mathrm{E}-02$ \\
\hline Oligopeptide transporter 1- & DN62436_c5_g1_i2::g.193429::m.193429 & 1.39 & 2.33E-04 \\
\hline Oligopeptide transporter 1-like & DN62707_c2_g1_i20::g.48777::m.48777 & 1.59 & 4.21E-03 \\
\hline Oligopeptide transporter 1-like & DN62707_c2_g1_i6::g.48758::m.48758 & 1.10 & $3.21 \mathrm{E}-03$ \\
\hline Lysine histidine transporter-like 8 & DN23033_c0_g1_i1::g.60538::m.60538 & 2.16 & $2.63 \mathrm{E}-03$ \\
\hline Lysine histidine transporter-like 8 & DN23033_c0_g2_i1::g.60539::m.60539 & 2.08 & $1.87 \mathrm{E}-02$ \\
\hline
\end{tabular}

\footnotetext{
${ }^{a}$ Functional annotations were assigned based on National Center for Biotechnology Information nonredundant database.

${ }^{b}$ Values were represented as $\log 2$ ratio; W2/W1 for week one versus week two (W1-W2) and W3/W2 for week two versus week three (W2-W3).

${ }^{\mathrm{c}}$ False discovery rate.
} 
symbiosis with saprotrophic fungi. It is noted that the expression of the $O$. sativa AM11 was dependent on a common symbiosis signaling pathway because the gene was not expressed in rice CSG mutants (Gutjahr et al. 2008). Taken together, these results indicate that not only the sequences of the major components such as CSG but also the expression patterns of genes related to the signaling pathway of mutualistic AM symbiosis are conserved in B. striata.

Based on a BLAST search of a sequence database of other orchids, a set of CSG is conserved in photosynthetic (i.e., initial mycoheterotrophic) orchids other than B. striata, indicating that CSG are conserved in a wide range of orchids. The presence of CSG in orchids is functionally and evolutionarily interesting because non-AM plants such as members of the Brassicaceae and Pinaceae families, which associate with the root-colonizing basidiomycete $P$. indica and ectomycorrhizal fungi, respectively, generally have a defective or partial set of CSG (Delaux et al. 2014; Garcia et al. 2015). These findings suggest that orchids have evolved differently than these non-AM plants, implying that there may be different types of endophytisms.

Perotto et al. (2014) reported that orchid cells harbor viable fungal structure pelotons and interact with OM fungi without strong defense activation in protocorms that is similar to AM symbiosis, whereas the OM fungi do not seem to be rewarded from the plant at the protocorm stage. This similarity is supported not only by ultrastructural observations (Hadley et al. 1971; Peterson and Massicotte 2004; Peterson et al. 1996; Uetake and Peterson 1998; Williamson and Hadley 1969) but also by the molecular-based evidence in this study. Given that certain features of the common symbiosis signaling pathway may predate the evolution of the first terrestrial plants that harbored AMlike associations (Delaux et al. 2015; Field et al. 2015; Martin et al. 2017), it is possible to speculate that orchids recruit a genetic system of AM symbiosis to establish mycoheterotrophic symbiosis. To address this speculation, future research will be needed to prove the necessity of the common symbiosis signaling pathway for establishment of mycoheterotrophic symbioses.

\section{MATERIALS AND METHODS}

\section{Plant materials and fungal strain.}

Seed of B. striata 'Murasakishikibu' and its symbiotic fungus, Tulasnella sp. strain HR1-1, were used in all experimental work. The origins of these plant and fungal lines have been described in detail previously (Yamamoto et al. 2017). Collected seed were stored at $4^{\circ} \mathrm{C}$ until they were used. Fungal colonies were cultivated on potato dextrose agar (PDA; Kyokuto, Tokyo) medium at $25^{\circ} \mathrm{C}$ until required for the symbiotic germination experiments. Seed of Lotus japonicus 'Gifu B-129' or ccamk-3 mutant were scarified, sterilized with sodium hypochlorite (1\% effective chloride), and soaked in sterilized water overnight. The seed were germinated on moist filter paper and grown in a growth chamber $\left(25^{\circ} \mathrm{C}\right.$, cycle of $16 \mathrm{~h}$ of light and $8 \mathrm{~h}$ of darkness).

\section{Symbiotic germination.}

Symbiotic germination procedures were performed according to the method of Yamamoto et al. (2017), with slight

Table 2. (Continued from previous page)

\begin{tabular}{|c|c|c|c|}
\hline Annotation $^{\text {a }}$ & Sequence ID & Fold change $^{b}$ & FDR $^{\mathbf{c}}$ \\
\hline Lysine histidine transporter 1-like & DN54457_c0_g5_i4::g.183467::m.183467 & 2.24 & $3.47 \mathrm{E}-02$ \\
\hline Lysine histidine transporter 1-like & DN54457_c0_g5_i8::g.183471::m.183471 & 2.27 & 2.94E-02 \\
\hline Sugar transporter ERD6-like 16 & DN59467_c6_g7_i18::g.119952::m.119952 & 1.27 & $6.52 \mathrm{E}-03$ \\
\hline Bidirectional sugar transporter SWEET16-like & DN39307_c0_g1_i1::g.79589::m.79589 & -1.39 & $9.08 \mathrm{E}-04$ \\
\hline Bidirectional sugar transporter SWEET16 & DN39307_c0_g1_i2::g.79591::m.79591 & -2.14 & $1.30 \mathrm{E}-02$ \\
\hline Bidirectional sugar transporter SWEET14-like & DN48582_c0_g1_i1::g.28310::m.28310 & 1.67 & $2.72 \mathrm{E}-07$ \\
\hline Bidirectional sugar transporter SWEET14-like & DN48582_c0_g1_i2::g.28312::m.28312 & 1.85 & $1.94 \mathrm{E}-08$ \\
\hline $\begin{array}{l}\text { Bidirectional sugar transporter SWEET2a-like } \\
\text { isoform X1 }\end{array}$ & DN53300_c0_g3_i10::g.155771::m.155771 & 1.32 & $2.37 \mathrm{E}-04$ \\
\hline Bidirectional sugar transporter SWEET2a-like & DN53300_c0_g3_i3::g.155766::m.155766 & 1.28 & $2.02 \mathrm{E}-03$ \\
\hline Bidirectional sugar transporter SWEET2a-like & DN53300_c0_g3_i4::g.155767::m.155767 & 1.08 & $3.15 \mathrm{E}-03$ \\
\hline Bidirectional sugar transporter SWEET6b-like & DN57552_c4_g1_i1::g.104408::m.104408 & 2.73 & $1.21 \mathrm{E}-10$ \\
\hline \multicolumn{4}{|l|}{ W2-W3 } \\
\hline Abscisic acid 8-hydroxylase 1-like & DN56235_c1_g2_i3::g.241237::m.241237 & 1.76 & $4.76 \mathrm{E}-02$ \\
\hline Abscisic acid 8-hydroxylase 1-like & DN56235_c1_g2_i1::g.241235::m.241235 & 1.79 & 4.23E-02 \\
\hline Di tri peptide transporter 2 & DN114729_c0_g1_i1::g.1994::m.1994 & 7.83 & $2.51 \mathrm{E}-02$ \\
\hline Germin $9-3$ & DN48078_c0_g2_i1::g.60695::m.60695 & 1.42 & $5.90 \mathrm{E}-03$ \\
\hline Late embryogenesis abundant At1g64065-like & DN52833_c2_g2_i1::g.252823::m.252823 & 2.50 & $6.78 \mathrm{E}-06$ \\
\hline Late embryogenesis abundant At1g64065-like & DN52833_c2_g2_i1::g.252824::m.252824 & 2.65 & $2.55 \mathrm{E}-05$ \\
\hline Probable aquaporin NIP-type & DN43429_c0_g2_i1::g.24704::m.24704 & -1.93 & 8.91E-03 \\
\hline Scarecrow 3 & DN47026_c0_g2_i1::g.173443::m.173443 & 1.17 & $1.36 \mathrm{E}-03$ \\
\hline Scarecrow 3 & DN47026_c0_g1_i1::g.173441::m.173441 & 1.38 & $1.78 \mathrm{E}-04$ \\
\hline Scarecrow 9 & DN61342_c2_g2_i1::g.74268::m.74268 & 1.07 & $6.86 \mathrm{E}-03$ \\
\hline Scarecrow 9 & DN61342_c2_g1_i1::g.74264::m.74264 & 1.08 & $3.89 \mathrm{E}-03$ \\
\hline Scarecrow 14 & DN61342_c2_g3_i1::g.74271::m.74271 & 1.64 & $5.04 \mathrm{E}-06$ \\
\hline Scarecrow 14 & DN61342_c2_g3_i2::g.74274::m.74274 & 1.69 & $5.66 \mathrm{E}-07$ \\
\hline Scarecrow 32 & DN50312_c0_g2_i3::g.195381::m.195381 & 1.08 & 4.18E-02 \\
\hline Scarecrow 32 & DN50312_c0_g2_i3::g.195386::m.195386 & 1.66 & 4.87E-02 \\
\hline Subtilisin-like protease & DN1702_c0_g1_i1::g.35886::m.35886 & -2.03 & $1.91 \mathrm{E}-02$ \\
\hline Subtilisin-like protease & DN35677_c0_g1_i1::g.181621::m.181621 & -3.63 & $4.96 \mathrm{E}-02$ \\
\hline Subtilisin-like protease & DN154153_c0_g1_i1::g.3731::m.3731 & -5.97 & $2.09 \mathrm{E}-02$ \\
\hline Vacuolar calcium ion transporter & DN55490_c0_g1_i3::g.216679::m.216679 & 2.46 & $1.05 \mathrm{E}-03$ \\
\hline Gibberellin $2-\beta$-dioxygenase-like & DN133591_c0_g1_i1::g.8098::m.8098 & -2.75 & $2.79 \mathrm{E}-02$ \\
\hline Auxin-induced 6B-like & DN6072_c0_g1_i1::g.185033::m.185033 & -2.23 & $6.74 \mathrm{E}-03$ \\
\hline Auxin-responsive SAUR50-like & DN138767_c0_-̄1_i1::g.226::m.226 & -3.50 & $1.92 \mathrm{E}-02$ \\
\hline OPT oligopeptide transporter & DN60623_c0_g2_i3::g.158828::m.158828 & 1.94 & $2.68 \mathrm{E}-02$ \\
\hline OPT oligopeptide transporter & DN60623_c0_g2_i5::g.158835::m.158835 & 2.06 & $3.14 \mathrm{E}-02$ \\
\hline Bidirectional sugar transporter SWEET16-like & DN39307_c0_g1_i1::g.79589::m.79589 & -1.54 & $1.58 \mathrm{E}-02$ \\
\hline
\end{tabular}


modifications as follows. Plates containing $20 \mathrm{ml}$ of oatmeal agar medium (Difco, Franklin, NJ, U.S.A.), either with or without sucrose at $30 \mathrm{~g} /$ liter, were inoculated with a culture of the symbiotic fungus and precultured for a week at $25^{\circ} \mathrm{C}$ before surface-sterilized seed were placed into the plates for symbiotic germination. The germination experiments were conducted at $25^{\circ} \mathrm{C}$ in the dark, and protocorms were collected every week for 3 weeks and stored at $-80^{\circ} \mathrm{C}$ for RNA extraction or in a formalin-acetic acid-alcohol (5\% formaldehyde, $5 \%$ acetic acid, and $45 \%$ ethanol) solution at $4{ }^{\circ} \mathrm{C}$ for fluorescent staining.

RNA preparation for transcriptome analysis.

Total RNA was extracted from $80 \mathrm{mg}$ of $B$. striata protocorms using an RNeasy Plant Kit (Qiagen, Hilden, Germany), in accordance with the manufacturer's protocol. The RNA was treated with RNase-free DNase I to remove residual genomic DNA and cleaned using an RNeasy Mini Kit (Qiagen) according to the manufacturer's protocol. The quality and quantity of the purified RNA was confirmed by measuring its absorbance at
260 and $280 \mathrm{~nm}$ using a NanoDrop ND-1000 spectrophotometer (Thermo Fisher Scientific, Waltham, MA, U.S.A.) and by electrophoresis using an Agilent 2100 Bioanalyzer (Agilent Technologies, Santa Clara, CA, U.S.A.). Three biological replicates were prepared for the transcriptome analysis.

\section{RNA sequencing and data analysis.}

RNA sequencing libraries were constructed from $1.0 \mu \mathrm{g}$ of total RNA using a TruSeq RNA Sample Prep Kit v2 and a TruSeq Stranded mRNA LT Sample Prep Kit (Illumina, San Diego, CA, U.S.A.) following the manufacturer's instructions. Following purification, the mRNA fragmentation, cDNA synthesis, and quality and quantity checks were performed according to the method described by Suetsugu et al. (2017). Multiplex sequencing of paired-end or single-end reads was performed on an Illumina HiSeq 1500 instrument at the NIBB Core Research Facilities (Okazaki, Japan), followed by raw data processing, base calling, and quality control using the manufacturer's standard pipeline with RTA, OLB, and CASAVA. Datasets of the
A

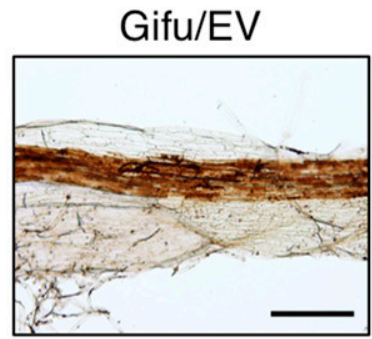

AM positive

/ GFP plants

B
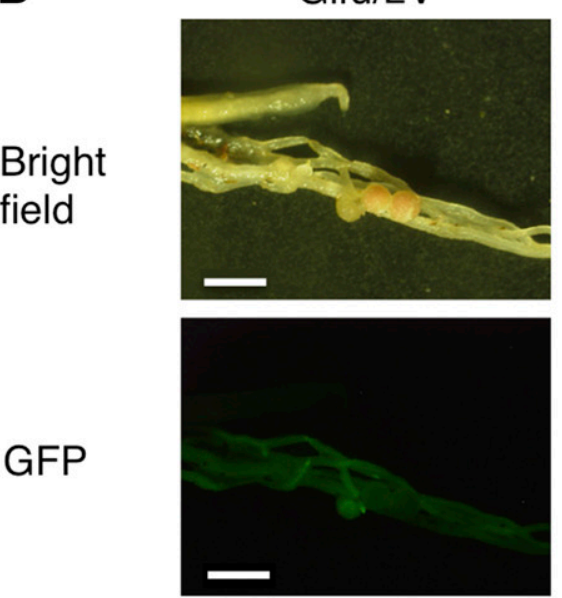

GFP

DsRED

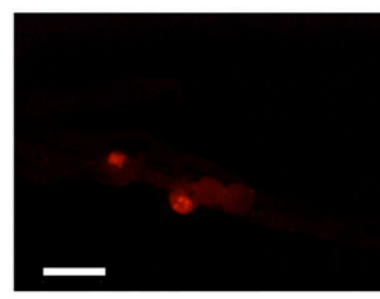

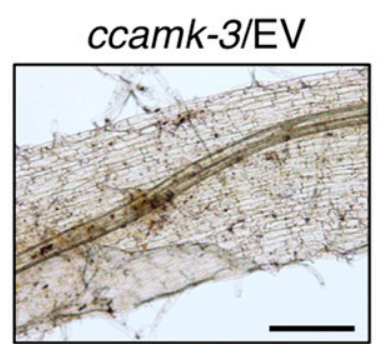

$0 / 34$
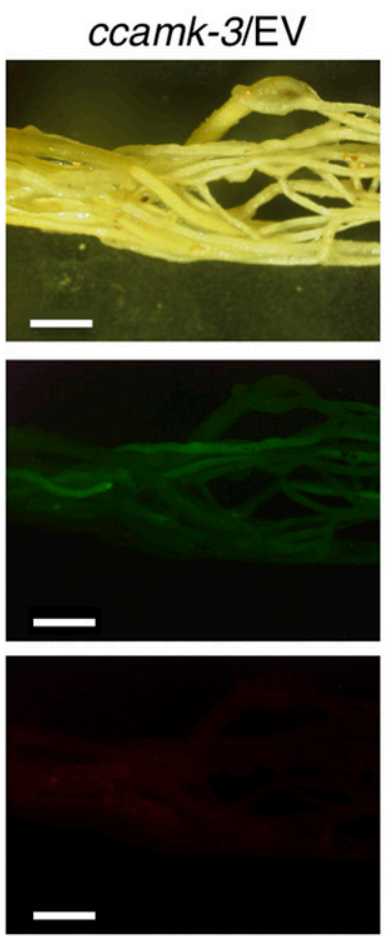

ccamk-3/LjCCaMK

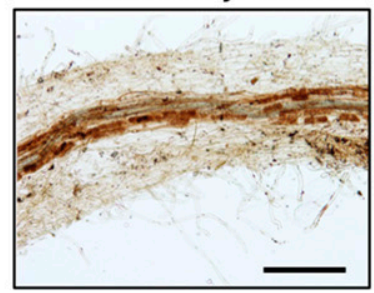

$21 / 45$

ccamk-3/LjCCaMK
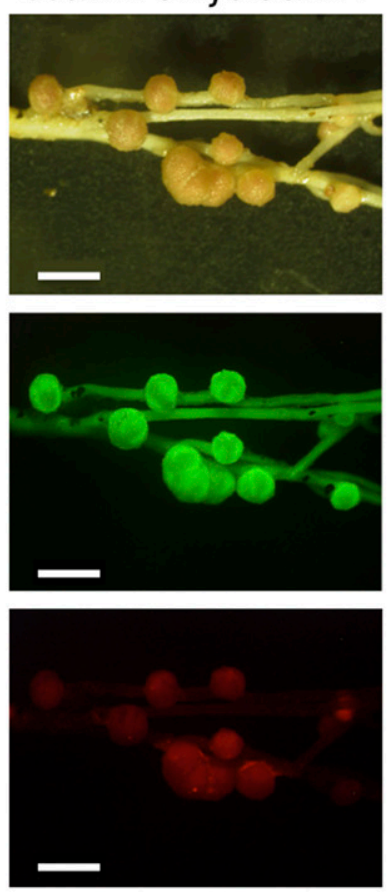

$20 / 25$

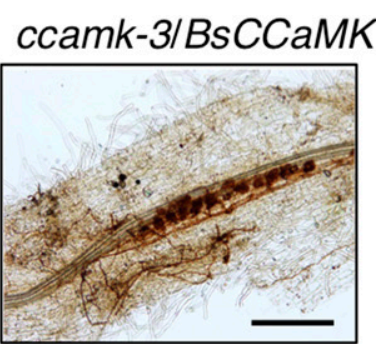

$15 / 43$
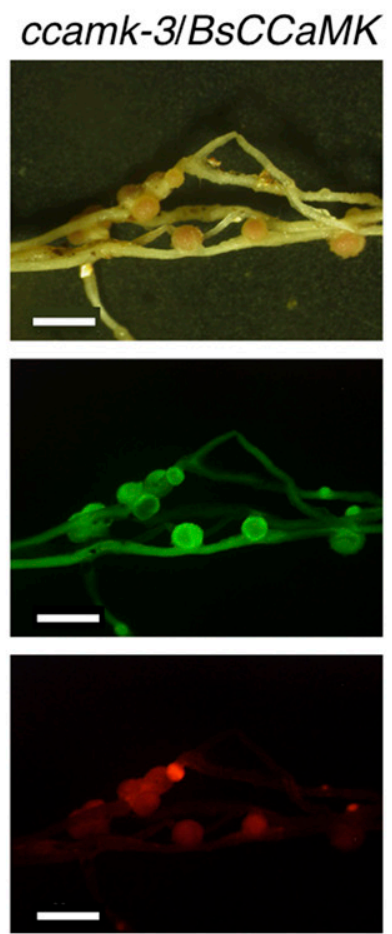

nodule positive

/ GFP plants 21/21

0/15

$21 / 29$

Fig. 3. Complementation of the Lotus japonicus ccamk-3 mutant with Bletilla striata CCaMK. Transgenic hairy roots carrying an empty vector (EV), $L j C C a M K$, or BsCCaMK were inoculated with A, Rhizophagus intraradices or B, Mesorhizobium loti expressing DsRed. All roots were observed after 4 weeks of growth under axenic conditions. GFP = green fluorescent protein. Scale bars: $200 \mu \mathrm{m}(\mathrm{A})$ and $20 \mathrm{~mm}(\mathrm{~B})$. 
short reads were registered in the DNA Data Bank of Japan (DDBJ) Sequence Read Archive (accession number DRA005999).

Construction and de novo assembly of RNA-seq data.

Prior to assembly, the reads were trimmed to remove lowquality ends ( $<$ QV30), and adapter sequences (parameter: $-\mathrm{o} 7)$ using the cutadapt program. Reads shorter than $50 \mathrm{bp}$ were removed. De novo assembly of the trimmed reads was conducted using Trinity, ver. 2.0.6 (Grabherr et al. 2011), with default settings. The coding sequences were predicted using TransDecoder with default settings (Haas et al. 2013). To reduce the sequence redundancy of the assembled transcript sequences, similar contigs were grouped using CD-HIT (parameter: -c sequence identity threshold $=0.98)(\mathrm{Li}$ and Godzik 2006). The nucleotide sequences of the assembly presented in this study are listed in Supplementary Dataset S1.

Fungal genome sequencing and de novo assembly.

Genomic DNA was extracted from Tulasnella grown on the PDA medium using a DNeasy Plant Mini Kit (Qiagen) and
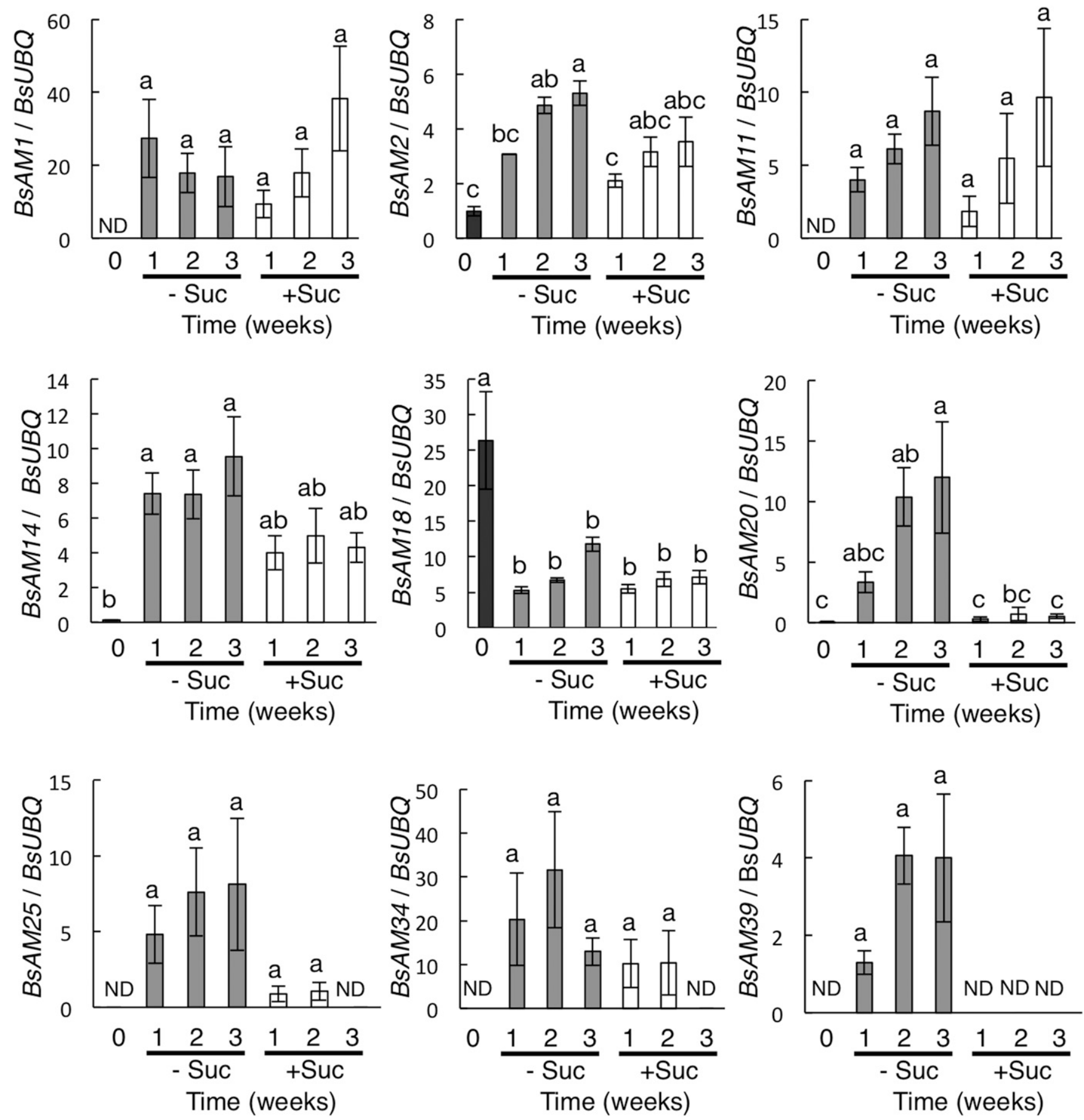

Fig. 4. Expression of Bletilla striata marker genes during symbiotic germination with Tulasnella sp. strain HR1-1. Quantitative reverse-transcription polymerase chain reaction was performed with total RNA isolated at different time points (week zero to week three of germination) and different conditions $(-$ Suc $=$ symbiotic germination on normal oatmeal agar medium and + Suc, symbiotic germination on oatmeal agar medium containing sucrose at 30 g/liter). Relative expression values were determined using the relative standard curve method. Error bars indicate standard error from three biological replicates. ND $=$ not detected. Different lowercase letters indicate significant differences between groups $(P<0.05$, Tukey-Kramer test $)$. 
purified using Genomic DNA Clean \& Concentrator (Zymo Research, Irvine, CA, U.S.A.) in accordance with the manufacturer's protocol. Size-selected genomic DNA libraries were prepared using the Pippin Prep system (Sage Science, Beverly, MA, U.S.A.) for paired-end libraries with a mean insert size of 350 or 800 bp and the Blue Pippin system (Sage Science) or electroelution were used for mate-pair libraries with large insert sizes ( $>4 \mathrm{kbp}$ ). The quality and quantity of the DNA library were confirmed with electrophoresis using an Agilent 2100 Bioanalyzer (Agilent Technologies), and with quantitative RT-PCR using an ABI 7500 Real-Time PCR system (Thermo Fisher Scientific). Multiple DNA libraries were sequenced using an Illumina MiSeq by PE150 v2 or PE300 v3 platform (Illumina). Datasets of the short reads were registered in the DDBJ Sequence Read Archive (accession number DRA006009). To remove contaminating reads, the sequence reads, including adapter sequences, were extracted from all mate-pair reads. After adapter trimming, de novo assembly, scaffolding, and gap closing were performed using Platanus, ver. 1.2.1 (Kajitani et al. 2014) with default parameters.

\section{Differential expression analysis.}

Data from three biological replicates were used in this analysis. To classify the single-end reads into sequences of plant and fungal origin, the reads were first mapped to the fungal genome using Bowtie2 (Langmead and Salzberg 2012). The unpaired reads classified as above were mapped to the de novo reference assembly of $B$. striata using Bowtie 2 and the transcript abundance was estimated using eXpress, ver. 1.5.1 (Roberts and Pachter 2013). Differences in library size were corrected using the trimmed mean of $\mathrm{M}$ value normalization method, and Edge $\mathrm{R}$ (Robinson et al. 2010) was used to identify DEG with a fold change $\geq 2.0$ or $\leq-2.0$ and FDR $<0.05$.

\section{Gene annotation and GO analysis.}

DEG were annotated using BLAST searches against the $\mathrm{nr}$ database. GO enrichment analysis of DEG was performed using BLAST2GO (Conesa et al. 2005) with one-sided Fisher's exact test (FDR < 0.05). The enrichment of DEG was calculated by comparing the de novo reference assembly of plant-derived sequences.

\section{Plasmid construction.}

The promoter region of $L j U B Q 10$, which is expressed constitutively in L. japonicus (Guether et al. 2009), was amplified by PCR from the L. japonicus TAC clone LjT06D07 using Prime STAR HS DNA Polymerase (Takara Bio Inc., Kusatsu, Japan) according to the manufacturer's protocol. The gene-specific primers used are shown in Supplementary Table S9. The amplified DNA was cloned into pDONR/Zeo (Thermo Fisher Scientific), then transferred into the Gateway-compatible binary vector pKGWFS7 (Karimi et al. 2002). This construct was used as a negative control for the complementation analysis. The $B s C C a M K$ cDNA was obtained by performing an RT-PCR on the total RNA of the B. striata protocorms using the Prime Script II first-strand cDNA synthesis kit (Takara Bio Inc.) following the manufacturer's protocol. BsCCaMK was amplified using Prime STAR HS DNA polymerase (Takara Bio Inc.) and gene-specific primers; then, the amplified cDNA was cloned into pENTR/DTOPO (Thermo Fisher Scientific). The BsCCaMK entry clone and the $L j C C a M K$ entry clone (Yano et al. 2008) were transferred into the Gateway-compatible binary vector pUB-GW-GFP carrying the reporter green fluorescent protein (GFP) gene driven by $35 S$ promoter (Maekawa et al. 2008).

\section{Complementation analysis.}

The empty vector plasmid or the pUB-GW-GFP vectors carrying the $B s C C a M K$ or $L j C C a M K$ constructs were transformed into the ccamk-3 mutant of L. japonicus (Tirichine et al. 2006) using hairy-root transformation mediated by Agrobacterium rhizogenes AR1193, as previously described (Maeda et al. 2006). Plants with GFP-positive hairy roots were selected and transplanted into pots of sterilized river sand and vermiculite (2:1 [vol/vol]) supplied with 1/10-strength Hoagland solution containing $0.1 \mathrm{mM} \mathrm{KNO}_{3}$ for the AM fungi infection assay or $\mathrm{B} \& \mathrm{D}$ medium containing $0.5 \mathrm{mM} \mathrm{KNO}_{3}$ for the nodulation assay. Seven days after transplantation, R. irregularis DAOM 197198 (Premier Tech, Quebec, QC, Canada) or M. loti MAFF 303099 constitutively expressing DsRed (Maekawa et al. 2009) were used to inoculate plants for the AM fungal infection and nodulation assays, respectively. The plants were grown for 4 weeks in a growth cabinet under axenic conditions $\left(25^{\circ} \mathrm{C}\right.$, cycle of $16 \mathrm{~h}$ of light and $8 \mathrm{~h}$ of darkness). The colonization phenotypes of the $R$. irregularis-inoculated roots were observed under a SZX16 stereomicroscope (Olympus, Tokyo) and an BX53 optical microscope (Olympus) after diaminobenzidine staining (Kobae and Ohtomo 2016). The nodulation phenotypes of $M$. loti-inoculated roots were examined under a Multi Viewer System VB-S20 fluorescence microscope (Keyence, Osaka, Japan).

\section{Gene expression analysis.}

Protocorms were harvested and stored at $-80^{\circ} \mathrm{C}$ until they were used for RNA extraction. Total RNA was extracted from $5 \mathrm{mg}$ of $B$. striata protocorms or 50 hand-sectioned protocorms for each condition using RNAiso Plus (Takara Bio Inc.), following the manufacturer's protocol. First-strand cDNA synthesis was performed using the ReverTra Ace qPCR RT Master Mix with gDNA Remover (Toyobo, Osaka, Japan) in accordance with the manufacturer's protocol. Quantitative RT-PCR assays were carried out using the THUNDERBIRD SYBR qPCR Mix (Toyobo) on a CFX connect real-time detection system (Bio-Rad Laboratories, Hercules, CA) using the following program: $95^{\circ} \mathrm{C}$ for $10 \mathrm{~min}$; 25 cycles of $95^{\circ} \mathrm{C}$ for $30 \mathrm{~s}, 60^{\circ} \mathrm{C}$ for $30 \mathrm{~s}$, and $72^{\circ} \mathrm{C}$ for $30 \mathrm{~s}$; and a final extension at $72^{\circ} \mathrm{C}$ for $5 \mathrm{~min}$. Fold changes were calculated using the expression of a housekeeping gene, UBIQUITIN5, as the internal control. Three technical replicates and three biological replicates were performed for each sample, and their threshold cycle values were averaged.

\section{ACKNOWLEDGMENTS}

We thank M. Hayashi, M. Kawaguchi, and N. Takeda for providing the bacteria strains; Y. Furui for gene expression analyses; and Y. Iguchi for constructing the plasmids. We also thank the National Institute for Basic Biology (NIBB) for supporting the RNA sequencing and fungal genome sequencing experiments, and the National BioResource Project Legume Base for providing L. japonicus B-129 seed and the TAC clone LjT06D07.

\section{LITERATURE CITED}

Atwood, J. T. 1986. The size of orchidacea and the systematic distribution of epiphytic orchids. Selbayana 9:171-186.

Banba, M., Gutjahr, C., Miyao, A., Hirochika, H., Paszkowski, U., Kouchi, H., and Imaizumi-Anraku, H. 2008. Divergence of evolutionary ways among common sym genes: CASTOR and CCaMK show functional conservation between two symbiosis systems and constitute the root of a common signaling pathway. Plant Cell Physiol. 49: 1659-1671.

Beyrle, H. F., Smith, S. E., Franco, C. M. M., and Peterson, R. L. 1995 Colonization of Orchis morio protocorms by a mycorrhizal fungus: Effects of nitrogen nutrition and glyphosate in modifying the responses. Can. J. Bot. 73:1128-1140.

Cameron, D. D., Johnson, I., Leake, J. R., and Read, D. J. 2007. Mycorrhizal acquisition of inorganic phosphorus by the green-leaved terrestrial orchid Goodyera repens. Ann. Bot. 99:831-834.

Cameron, D. D., Johnson, I., Read, D. J., and Leake, J. R. 2008. Giving and receiving: Measuring the carbon cost of mycorrhizas in the green orchid, Goodyera repens. New Phytol. 180:176-184. 
Cameron, D. D., Leake, J. R., and Read, D. J. 2006. Mutualistic mycorrhiza in orchids: Evidence from plant-fungus carbon and nitrogen transfers in the green-leaved terrestrial orchid Goodyera repens. New Phytol. 171: 405-416.

Chase, M. W., Cameron, K. M., Freudenstein, J. V., Pridgeon, A. M., Salazar, G., van den Berg, C., and Schuiteman, A. 2015. An updated classification of Orchidaceae. Bot. J. Linn. Soc. 177:151-174.

Chen, C., Gao, M., Liu, J., and Zhu, H. 2007. Fungal symbiosis in rice requires an ortholog of a legume common symbiosis gene encoding a $\mathrm{Ca}^{2+} /$ calmodulin-dependent protein kinase. Plant Physiol. 145:1619-1628.

Conesa, A., Götz, S., García-Gómez, J. M., Terol, J., Talón, M., and Robles, M. 2005. Blast2GO: A universal tool for annotation, visualization and analysis in functional genomics research. Bioinformatics 21:3674-3676.

Dearnaley, J., Perotto, S., and Selosse, M. A. 2016. Structure and development of orchid mycorrhizas. Pages 63-86 in: Molecular Mycorrhizal Symbiosis. F. Martin, ed. John Wiley \& Sons, Hoboken, NJ, U.S.A.

Delaux, P. M., Radhakrishnan, G. V., Jayaraman, D., Cheema, J., Malbreil, M., Volkening, J. D., Sekimoto, H., Nishiyama, T., Melkonian, M., Pokorny, L., Rothfels, C. J., Sederoff, H. W., Stevenson, D. W., Surek, B., Zhang, Y., Sussman, M. R., Dunand, C., Morris, R. J., Roux, C., Wong, G. K. S., Oldroyd, G. E. D., and Ané, J. M. 2015. Algal ancestor of land plants was preadapted for symbiosis. Proc. Natl. Acad. Sci. U.S.A. 112:13390-13395.

Delaux, P. M., Séjalon-Delmas, N., Bécard, G., and Ané, J. M. 2013. Evolution of the plant-microbe symbiotic 'toolkit'. Trends Plant Sci. 18: 298-304.

Delaux, P. M., Varala, K., Edger, P. P., Coruzzi, G. M., Pires, J. C., and Ané, J. M. 2014. Comparative phylogenomics uncovers the impact of symbiotic associations on host genome evolution. PLoS Genet. 10:e1004487.

Field, K. J., Pressel, S., Duckett, J. G., Rimington, W. R., and Bidartondo, M. I. 2015. Symbiotic options for the conquest of land. Trends Ecol. Evol. 30:477-486.

Floudas, D., Binder, M., Riley, R., Barry, K., Blanchette, R. A., Henrissat, B., Martínez, A. T., Otillar, R., Spatafora, J. W., Yadav, J. S., Aerts, A., Benoit, I., Boyd, A., Carlson, A., Copeland, A., Coutinho, P. M., de Vries, R. P., Ferreira, P., Findley, K., Foster, B., Gaskell, J., Glotzer, D. Górecki, P., Heitman, J., Hesse, C., Hori, C., Igarashi, K., Jurgens, J. A., Kallen, N., Kersten, P., Kohler, A., Kües, U., Kumar, T. K. A., Kuo, A., LaButti, K., Larrondo, L. F., Lindquist, E., Ling, A., Lombard, V., Lucas, S., Lundell, T., Martin, R., McLaughlin, D. J., Morgenstern, I., Morin, E., Murat, C., Nagy, L. G., Nolan, M., Ohm, R. A., Patyshakuliyeva, A., Rokas, A., Ruiz-Dueñas, F. J., Sabat, G., Salamov, A., Samejima, M., Schmutz, J., Slot, J. C., St John, F., Stenlid, J., Sun, H., Sun, S., Syed, K., Tsang, A., Wiebenga, A., Young, D., Pisabarro, A., Eastwood, D. C., Martin, F., Cullen, D., Grigoriev, I. V., and Hibbett, D. S. 2012. The Paleozoic origin of enzymatic lignin decomposition reconstructed from 31 fungal genomes. Science 336:1715-1719.

Fochi, V., Chitarra, W., Kohler, A., Voyron, S., Singan, V. R., Lindquist, E. A., Barry, K. W., Girlanda, M., Grigoriev, I. V., Martin, F., Balestrini, R., and Perotto, S. 2017. Fungal and plant gene expression in the Tulasnella calospora-Serapias vomeracea symbiosis provides clues about nitrogen pathways in orchid mycorrhizas. New Phytol. 213: 365-379.

Garcia, K., Delaux, P. M., Cope, K. R., and Ané, J. M. 2015. Molecular signals required for the establishment and maintenance of ectomycorrhizal symbioses. New Phytol. 208:79-87.

Genre, A., and Russo, G. 2016. Does a common pathway transduce symbiotic signals in plant-microbe interactions? Front. Plant Sci. 7:96.

Givnish, T. J., Spalink, D., Ames, M., Lyon, S. P., Hunter, S. J., Zuluaga, A., Iles, W. J. D., Clements, M. A., Arroyo, M. T. K., Leebens-Mack, J., Endara, L., Kriebel, R., Neubig, K. M., Whitten, W. M., Williams, N. H., and Cameron, K. M. 2015. Orchid phylogenomics and multiple drivers of their extraordinary diversification. Proc. R. Soc. B Biol. Sci. 282: 20151553.

Godfroy, O., Debellé, F., Timmers, T., and Rosenberg, C. 2006. A rice calcium- and calmodulin-dependent protein kinase restores nodulation to a legume mutant. Mol. Plant-Microbe Interact. 19:495-501.

Grabherr, M. G., Haas, B. J., Yassour, M., Levin, J. Z., Thompson, D. A., Amit, I., Adiconis, X., Fan, L., Raychowdhury, R., Zeng, Q., Chen, Z., Mauceli, E., Hacohen, N., Gnirke, A., Rhind, N., di Palma, F., Birren, B. W., Nusbaum, C., Lindblad-Toh, K., Friedman, N., and Regev, A. 2011. Full-length transcriptome assembly from RNA-Seq data without a reference genome. Nat. Biotechnol. 29:644-652.

Groth, M., Takeda, N., Perry, J., Uchida, H., Dräxl, S., Brachmann, A., Sato, S., Tabata, S., Kawaguchi, M., Wang, T. L., and Parniske, M. 2010. NENA, a Lotus japonicus homolog of Sec13, is required for rhizodermal infection by arbuscular mycorrhiza fungi and rhizobia but dispensable for cortical endosymbiotic development. Plant Cell 22:2509-2526.

Guether, M., Balestrini, R., Hannah, M., He, J., Udvardi, M. K., and Bonfante, P. 2009. Genome-wide reprogramming of regulatory networks, transport, cell wall and membrane biogenesis during arbuscular mycorrhizal symbiosis in Lotus japonicus. New Phytol. 182: 200-212.

Gutjahr, C. 2014. Phytohormone signaling in arbuscular mycorhiza development. Curr. Opin. Plant Biol. 20:26-34.

Gutjahr, C., Banba, M., Croset, V., An, K., Miyao, A., An, G., Hirochika, H., Imaizumi-Anraku, H., and Paszkowski, U. 2008. Arbuscular mycorrhizaspecific signaling in rice transcends the common symbiosis signaling pathway. Plant Cell 20:2989-3005.

Haas, B. J., Papanicolaou, A., Yassour, M., Grabherr, M., Blood, P. D., Bowden, J., Couger, M. B., Eccles, D., Li, B., Lieber, M., MacManes, M. D., Ott, M., Orvis, J., Pochet, N., Strozzi, F., Weeks, N., Westerman, R., William, T., Dewey, C. N., Henschel, R., LeDuc, R. D., Friedman, N., and Regev, A. 2013. De novo transcript sequence reconstruction from RNA-seq using the Trinity platform for reference generation and analysis. Nat. Protoc. 8:1494-1512.

Hadley, G., Johnson, R. P. C., and John, D. A. 1971. Fine structure of the host-fungus interface in orchid mycorrhiza. Planta 100:191-199.

Handa, Y., Nishide, H., Takeda, N., Suzuki, Y., Kawaguchi, M., and Saito, K. 2015. RNA-seq Transcriptional Profiling of an Arbuscular Mycorrhiza Provides Insights into Regulated and Coordinated Gene Expression in Lotus japonicus and Rhizophagus irregularis. Plant Cell Physiol. 56: 1490-1511.

Harvais, G., and Hadley, G. 1967. The development of Orchis purpurella in asymbiotic and inoculated cultures. New Phytol. 66:217-230.

Hause, B., Mrosk, C., Isayenkov, S., and Strack, D. 2007. Jasmonates in arbuscular mycorrhizal interactions. Phytochemistry 68:101-110.

Imaizumi-Anraku, H., Takeda, N., Charpentier, M., Perry, J., Miwa, H., Umehara, Y., Kouchi, H., Murakami, Y., Mulder, L., Vickers, K., Pike, J., Downie, J. A., Wang, T., Sato, S., Asamizu, E., Tabata, S., Yoshikawa, M., Murooka, Y., Wu, G.-J., Kawaguchi, M., Kawasaki, S., Parniske, M., and Hayashi, M. 2004. Plastid proteins crucial for symbiotic fungal and bacterial entry into plant roots. Nature 433:527-531.

Imhof, S., Massicotte, H. B., Melville, L. H., and Peterson, R. L. 2013. Subterranean morphology and mycorrhizal structures. Pages 157-214 in: Mycoheterotrophy. V. F. S. T. Merckx, ed. Springer, New York.

Juge, N. 2006. Plant protein inhibitors of cell wall degrading enzymes. Trends Plant Sci. 11:359-367.

Kajitani, R., Toshimoto, K., Noguchi, H., Toyoda, A., Ogura, Y., Okuno, M., Yabana, M., Harada, M., Nagayasu, E., Maruyama, H., Kohara, Y. Fujiyama, A., Hayashi, T., and Itoh, T. 2014. Efficient de novo assembly of highly heterozygous genomes from whole-genome shotgun short reads. Genome Res. 24:1384-1395.

Kanamori, N., Madsen, L. H., Radutoiu, S., Frantescu, M., Quistgaard, E. M. H., Miwa, H., Downie, J. A., James, E. K., Felle, H. H., Haaning, L. L., Jensen, T. H., Sato, S., Nakamura, Y., Tabata, S., Sandal, N., and Stougaard, J. 2006. A nucleoporin is required for induction of $\mathrm{Ca}^{2+}$ spiking in legume nodule development and essential for rhizobial and fungal symbiosis. Proc. Natl. Acad. Sci. U.S.A. 103:359-364.

Karimi, M., Inzé, D., and Depicker, A. 2002. GATEWAY vectors for Agrobacterium-mediated plant transformation. Trends Plant Sci. 7: 193-195.

Kiers, E. T., Duhamel, M., Beesetty, Y., Mensah, J. A., Franken, O., Verbruggen, E., Fellbaum, C. R., Kowalchuk, G. A., Hart, M. M., Bago, A., Palmer, T. M., West, S. A., Vandenkoornhuyse, P., Jansa, J., and Bücking, H. 2011. Reciprocal rewards stabilize cooperation in the mycorrhizal symbiosis. Science 333:880-882.

Kistner, C., Winzer, T., Pitzschke, A., Mulder, L., Sato, S., Kaneko, T., Tabata, S., Sandal, N., Stougaard, J., Webb, K. J., Szczyglowski, K., and Parniske, M. 2005. Seven Lotus japonicus genes required for transcriptional reprogramming of the root during fungal and bacterial symbiosis. Plant Cell 17:2217-2229.

Kloppholz, S., Kuhn, H., and Requena, N. 2011. A secreted fungal effector of Glomus intraradices promotes symbiotic biotrophy. Curr. Biol. 21: 1204-1209.

Kobae, Y., and Ohtomo, R. 2016. An improved method for bright-field imaging of arbuscular mycorrhizal fungi in plant roots. Soil Sci. Plant Nutr. 768:1-4.

Kuga, Y., Sakamoto, N., and Yurimoto, H. 2014. Stable isotope cellular imaging reveals that both live and degenerating fungal pelotons transfer carbon and nitrogen to orchid protocorms. New Phytol. 202: 594-605.

Lahrmann, U., Strehmel, N., Langen, G., Frerigmann, H., Leson, L., Ding, Y., Scheel, D., Herklotz, S., Hilbert, M., and Zuccaro, A. 2015. 
Mutualistic root endophytism is not associated with the reduction of saprotrophic traits and requires a noncompromised plant innate immunity. New Phytol. 207:841-857.

Langmead, B., and Salzberg, S. L. 2012. Fast gapped-read alignment with Bowtie 2. Nat. Methods 9:357-359.

Leake, J. R. 1994. The biology of myco-heterotrophic ('saprophytic') plants. New Phytol. 127:171-216.

Leake, J. R., Cameron, D. D., and Beerling, D. J. 2008. Fungal fidelity in the myco-heterotroph-to-autotroph life cycle of Lycopodiaceae: A case of parental nurture? New Phytol. 177:572-576.

Li, W., and Godzik, A. 2006. Cd-hit: A fast program for clustering and comparing large sets of protein or nucleotide sequences. Bioinformatics 22:1658-1659.

Lu, H. C., Hsieh, M. H., Chen, C.-E., Chen, H. H., Wang, H. I., and Yeh, H. H. 2012. A high-throughput virus-induced gene-silencing vector for screening transcription factors in virus-induced plant defense response in orchid. Mol. Plant-Microbe Interact. 25:738-746.

Maeda, D., Ashida, K., Iguchi, K., Chechetka, S. A., Hijikata, A., Okusako, Y., Deguchi, Y., Izui, K., and Hata, S. 2006. Knockdown of an arbuscular mycorrhiza-inducible phosphate transporter gene of Lotus japonicus suppresses mutualistic symbiosis. Plant Cell Physiol. 47: 807-817.

Maekawa, T., Kusakabe, M., Shimoda, Y., Sato, S., Tabata, S., Murooka, Y., and Hayashi, M. 2008. Polyubiquitin promoter-based binary vectors for overexpression and gene silencing in Lotus japonicus. Mol. PlantMicrobe Interact. 21:375-382.

Maekawa, T., Maekawa-Yoshikawa, M., Takeda, N., Imaizumi-Anraku, H., Murooka, Y., and Hayashi, M. 2009. Gibberellin controls the nodulation signaling pathway in Lotus japonicus. Plant J. 58:183-194.

Martin, F. M., Uroz, S., and Barker, D. G. 2017. Ancestral alliances: Plant mutualistic symbioses with fungi and bacteria. Science 356:eaad4501.

Martos, F., Dulormne, M., Pailler, T., Bonfante, P., Faccio, A., Fournel, J., Dubois, M. P., and Selosse, M. A. 2009. Independent recruitment of saprotrophic fungi as mycorrhizal partners by tropical achlorophyllous orchids. New Phytol. 184:668-681.

Masuhara, G., and Katsuya, K. 1989. Effects of mycorrhizal fungi on seed germination and early growth of three Japanese terrestrial orchids. Sci. Hortic. (Amsterdam) 37:331-337.

McGinnis, S., and Madden, T. L. 2004. BLAST: At the core of a powerful and diverse set of sequence analysis tools. Nucleic Acids Res. 32: W20-W25.

Merckx, V. S. F. T., ed. 2013. Mycoheterotrophy: An introduction. Pages 1-17 in: Mycoheterotrophy. V. F. S. T. Merckx, ed. Springer, New York.

Ogura-Tsujita, Y., Gebauer, G., Hashimoto, T., Umata, H., and Yukawa, T. 2009. Evidence for novel and specialized mycorrhizal parasitism: The orchid Gastrodia confusa gains carbon from saprotrophic Mycena. Proc. Biol. Sci. 276:761-767.

Parniske, M. 2008. Arbuscular mycorrhiza: The mother of plant root endosymbioses. Nat. Rev. Microbiol. 6:763-775.

Perotto, S., Rodda, M., Benetti, A., Sillo, F., Ercole, E., Rodda, M., Girlanda, M., Murat, C., and Balestrini, R. 2014. Gene expression in mycorrhizal orchid protocorms suggests a friendly plant-fungus relationship. Planta 239:1337-1349.

Peterson, R. L., and Massicotte, H. B. 2004. Exploring structural definitions of mycorrhizas, with emphasis on nutrient-exchange interfaces. Can. J. Bot. 82:1074-1088.

Peterson, R. L., Uetake, Y., Bonfante, P., and Faccio, A. 1996. The interface between fungal hyphae and orchid protocorm cells. Can. J. Bot. 74: 1861-1870.

Plett, J. M., Daguerre, Y., Wittulsky, S., Vayssières, A., Deveau, A., Melton, S. J., Kohler, A., Morrell-Falvey, J. L., Brun, A., Veneault-Fourrey, C., and Martin, F. 2014. Effector MiSSP7 of the mutualistic fungus Laccaria bicolor stabilizes the Populus JAZ6 protein and represses jasmonic acid (JA) responsive genes. Proc. Natl. Acad. Sci. U.S.A. 111:8299-8304.

Rasmussen, H., and Rasmussen, F. 2007. Trophic relationships in orchid mycorrizha-Diversity and implications for conservation. Lankesteriana 7:334-341.

Rivas, S. 2012. Nuclear dynamics during plant innate immunity. Plant Physiol. 158:87-94.

Roberts, A., and Pachter, L. 2013. Streaming fragment assignment for realtime analysis of sequencing experiments. Nat. Methods 10:71-73.

Robinson, M. D., McCarthy, D. J., and Smyth, G. K. 2010. edgeR: A Bioconductor package for differential expression analysis of digital gene expression data. Bioinformatics 26:139-140.

Saito, K., Yoshikawa, M., Yano, K., Miwa, H., Uchida, H., Asamizu, E., Sato, S., Tabata, S., Imaizumi-Anraku, H., Umehara, Y., Kouchi, H.,
Murooka, Y., Szczyglowski, K., Downie, J. A., Parniske, M., Hayashi, M., and Kawaguchi, M. 2007. NUCLEOPORIN85 is required for calcium spiking, fungal and bacterial symbioses, and seed production in Lotus japonicus. Plant Cell 19:610-624.

Selosse, M. A., Dubois, M. P., and Alvarez, N. 2009. Do Sebacinales commonly associate with plant roots as endophytes? Mycol. Res. 113: 1062-1069.

Selosse, M. A., and Martos, F. 2014. Do chlorophyllous orchids heterotrophically use mycorrhizal fungal carbon? Trends Plant Sci. 19: 683-685.

Selosse, M. A., and Roy, M. 2009. Green plants that feed on fungi: Facts and questions about mixotrophy. Trends Plant Sci. 14:64-70.

Selosse, M. A., Schneider-Maunoury, L., and Martos, F. 2018. Time to rethink fungal ecology? Fungal ecological niches are often prejudged. New Phytol. 217:968-972.

Shimura, H., and Koda, Y. 2005. Enhanced symbiotic seed germination of Cypripedium macranthos var. rebunense following inoculation after cold treatment. Physiol. Plant. 123:281-287.

Smith, S. E., and Read, F. A., eds. 2008. Mycorrhizal Symbiosis, 3rd ed. Academic Press. London.

Spatafora, J. W., Chang, Y., Benny, G. L., Lazarus, K., Smith, M. E., Berbee, M. L., Bonito, G., Corradi, N., Grigoriev, I., Gryganskyi, A., James, T. Y., O’Donnell, K., Roberson, R. W., Taylor, T. N., Uehling, J., Vilgalys, R., White, M. M., and Stajich, J. E. 2017. A phylum-level phylogenetic classification of zygomycete fungi based on genome-scale data. Mycologia 108:1028-1046.

Stougaard, J. 2001. Genetics and genomics of root symbiosis. Curr. Opin. Plant Biol. 4:328-335.

Stracke, S., Kistner, C., Yoshida, S., Mulder, L., Sato, S., Kaneko, T., Tabata, S., Sandal, N., Stougaard, J., Szczyglowski, K., and Parniske, M. 2002. A plant receptor-like kinase required for both bacterial and fungal symbiosis. Nature 417:959-962.

Suetsugu, K., Yamato, M., Miura, C., Yamaguchi, K., Takahashi, K., Ida, Y., Shigenobu, S., and Kaminaka, H. 2017. Comparison of green and albino individuals of the partially mycoheterotrophic orchid Epipactis helleborine on molecular identities of mycorrhizal fungi, nutritional modes and gene expression in mycorrhizal roots. Mol. Ecol. 26: 1652-1669.

Svistoonoff, S., Benabdoun, F. M., Nambiar-Veetil, M., Imanishi, L., Vaissayre, V., Cesari, S., Diagne, N., Hocher, V., de Billy, F., Bonneau, J., Wall, L., Ykhlef, N., Rosenberg, C., Bogusz, D., Franche, C., and Gherbi, H. 2013. The independent acquisition of plant root nitrogenfixing symbiosis in Fabids recruited the same genetic pathway for nodule organogenesis. PLoS One 8:e64515.

Takeda, N., Handa, Y., Tsuzuki, S., Kojima, M., Sakakibara, H., and Kawaguchi, M. 2015. Gibberellins interfere with symbiosis signaling and gene expression and alter colonization by arbuscular mycorrhizal fungi in Lotus japonicus. Plant Physiol. 167: 545-557.

Takeda, N., Maekawa, T., and Hayashi, M. 2012. Nuclear-localized and deregulated calcium- and calmodulin-dependent protein kinase activates rhizobial and mycorrhizal responses in Lotus japonicus. Plant Cell 24: 810-822.

Tirichine, L., Imaizumi-Anraku, H., Yoshida, S., Murakami, Y., Madsen, L. H., Miwa, H., Nakagawa, T., Sandal, N., Albrektsen, A. S., Kawaguchi, M., Downie, A., Sato, S., Tabata, S., Kouchi, H., Parniske, M., Kawasaki, S., and Stougaard, J. 2006. Deregulation of a $\mathrm{Ca}^{2+} /$ calmodulin-dependent kinase leads to spontaneous nodule development. Nature 441:1153-1156.

Uetake, Y., and Peterson, R. L. 1998. Association between microtubules and symbiotic fungal hyphae in protocorm cells of the orchid species, Spiranthes sinensis. New Phytol. 140:715-722.

van der Heijden, M. G. A., Martin, F. M., Selosse, M. A., and Sanders, I. R. 2015. Mycorrhizal ecology and evolution: The past, the present, and the future. New Phytol. 205:1406-1423.

Weiß, M., Waller, F., Zuccaro, A., and Selosse, M. A. 2016. Sebacinales-One thousand and one interactions with land plants. New Phytol. 211:20-40.

Williamson, B., and Hadley, G. 1969. DNA content of nuclei in orchid protocorms symbiotically infected with Rhizoctonia. Nature 222: 582-583.

Yamamoto, T., Miura, C., Fuji, M., Nagata, S., Otani, Y., Yagame, T., Yamato, M., and Kaminaka, H. 2017. Quantitative evaluation of protocorm growth and fungal colonization in Bletilla striata (Orchidaceae) reveals less-productive symbiosis with a non-native symbiotic fungus. BMC Plant Biol. 17:50.

Yano, K., Yoshida, S., Müller, J., Singh, S., Banba, M., Vickers, K., Markmann, K., White, C., Schuller, B., Sato, S., Asamizu, E., Tabata, S., 
Murooka, Y., Perry, J., Wang, T. L., Kawaguchi, M., Imaizumi-Anraku, H., Hayashi, M., and Parniske, M. 2008. CYCLOPS, a mediator of symbiotic intracellular accommodation. Proc. Natl. Acad. Sci. U.S.A. 105:20540-20545.

Zhao, M. M., Zhang, G., Zhang, D. W., Hsiao, Y. Y., and Guo, S. X. 2013 ESTs analysis reveals putative genes involved in symbiotic seed germination in Dendrobium officinale. PLoS One 8:e72705.

Zhao, X., Zhang, J., Chen, C., Yang, J., Zhu, H., Liu, M., and Lv, F. 2014. Deep sequencing-based comparative transcriptional profiles of Cymbidium hybridum roots in response to mycorrhizal and non-mycorrhizal beneficial fungi. BMC Genomics 15:747.
Zhu, H., Riely, B. K., Burns, N. J., and Ané, J. M. 2006. Tracing nonlegume orthologs of legume genes required for nodulation and arbuscular mycorrhizal symbioses. Genetics 172:2491-2499.

\section{AUTHOR-RECOMMENDED INTERNET RESOURCES}

cutadapt program: https://cutadapt.readthedocs.io/en/stable/ LegumeBase, NBRP Lotus/Glycine:

https://www.legumebase.brc.miyazaki-u.ac.jp/about.jsp MEGA software version 7: https://www.megasoftware.net/

R package: https://cran.r-project.org/web/packages/gplots/index.html 